DOCUMENTO DE TRABA JO

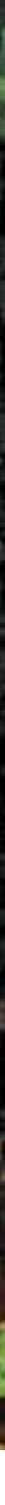

El aprovechamiento de madera en las concesiones castañeras (Bertholletia excelsa) en Madre de Dios, Perú

Un análisis de su situación normativa

Rosa E. Cossío-Solano

Manuel R. Guariguata

Mary Menton

José Luis Capella

Luisa Ríos

Pablo Peña
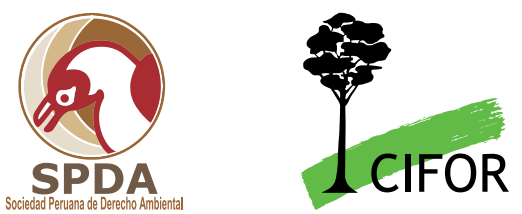



\section{El aprovechamiento de madera en las concesiones castañeras (Bertholletia excelsa) en Madre de Dios, Perú \\ Un análisis de su situación normativa}

Rosa E. Cossío-Solano

Manuel R. Guariguata

Mary Menton

José Luis Capella

Luisa Ríos

Pablo Peña 
Documento de trabajo 56

(C) 2011 Center for International Forestry Research

Todos los derechos reservados

Fotografías: Cesar Sabogal

Cossío-Solano, R.E., Guariguata, M.R., Menton, M., Capella, J.L., Ríos, L. y Peña, P. 2011 El aprovechamiento de madera en las concesiones castañeras (Bertholletia excelsa) en Madre de Dios, Perú: un análisis de su situación normativa. Documento de trabajo 56. CIFOR, Bogor, Indonesia

CIFOR

Jl. CIFOR, Situ Gede

Bogor Barat 16115

Indonesia

$T+62(251) 8622-622$

$F+62(251) 8622-100$

Ecifor@cgiar.org

\section{www.cifor.cgiar.org}

Cualquier opinión vertida en este documento es de los autores. No refleja necesariamente las opiniones de CIFOR, de las instituciones para las que los autores trabajan o de los financiadores. 


\section{Contenido}

Lista de figuras $\quad$ iv

Resumen v v

$\begin{array}{ll}\text { 1. Introducción } & 1\end{array}$

2. Marco legal para el aprovechamiento de recursos forestales maderables y no maderables 3

Generalidades $\quad 3$

Establecimiento de concesiones forestales maderables y no maderables en Madre de Dios 4

$\begin{array}{ll}\text { El aprovechamiento de castaña en concesiones castañeras } & 4\end{array}$

3. El aprovechamiento de madera en las concesiones castañeras 6

Dinámica regulatoria $\quad 6$

El debate sobre el aprovechamiento de madera en concesiones castañeras $r$

4. La dinámica del aprovechamiento de madera en concesiones castañeras y

en concesiones madereras entre 2004 y $2010 \quad 10$

Dinámica de la extracción de madera en las concesiones castañeras 10

Dinámica de la extracción de madera en las concesiones madereras $\quad 10$

5. Percepciones sobre la viabilidad de la extracción de madera en concesiones castañeras 14

Viabilidad técnica $\quad 14$

La intensidad de la extracción de madera como criterio numérico $\quad 14$

Aplicación del marco legal sobre el aprovechamiento madera en las concesiones castañeras 15

$\begin{array}{ll}\text { Conclusiones y recomendaciones } & 16\end{array}$

$\begin{array}{lr}\text { Referencias } & 18\end{array}$

Apéndices $\quad 19$

1. Normas que regulan la actividad castañera 19

2. Volúmenes totales de madera extraídos por hectárea por año en las concesiones castañeras reportados oficialmente en las Administraciones

Técnicas de Tahuamanu y Tambopata-Manu. Se presenta también el total para Madre de Dios. 21

3. Volúmenes totales de madera extraídos por año en las concesiones madereras reportados oficialmente en las Administraciones Técnicas de Tahuamanu y Tambopata-Manu. 22

4. Volúmenes promedio de madera extraídos por hectárea por año reportados oficialmente en las concesiones castañeras de Tahuamanu. 23

5. Volúmenes promedio de madera extraídos por hectárea por año reportados oficialmente en las concesiones castañeras de Tambopata-Manu. 24

6. Volúmenes promedio de madera extraídos por hectárea por año reportados oficialmente en las concesiones madereras de Tahuamanu 25

7. Volúmenes promedio de madera extraídos por hectárea por año reportados

8. Expertos consultados 29 


\section{Lista de figuras}

1. Distribución actual de las concesiones de castaña en el Departamento de Madre de Dios, Perú

2. Volúmenes oficiales extraídos de madera por hectárea por año en concesiones castañeras y concesiones madereras en Madre de Dios entre 2004 y 2010

3. Volúmenes extraídos de madera por hectárea por año en concesiones de castaña y concesiones de madera reportados oficialmente en las ATFFS de Tahuamanu y Tambopata-Manu entre 2004 y 2010

4. Distribución de frecuencia de volúmenes por hectárea de madera extraída según cifras oficiales en concesiones madereras y concesiones castañeras en Madre de Dios entre 2004 y 2010 en función del número de contratos de extracción

5. Volúmenes totales de madera extraídos según cifras oficiales en concesiones madereras y castañeras entre 2004 y 2010 en Madre de Dios 


\section{Resumen}

La extracción de madera es una de las actividades económicas de mayor importancia en el Departamento de Madre de Dios en la amazonia peruana. El objetivo de este documento es evaluar la situación del aprovechamiento de madera en las concesiones forestales para otros productos del bosque de Madre de Dios (en adelante concesiones castañeras) desde el año 2004, cuando se publicó la norma con carácter de complementariedad que permitió esta actividad y hasta la zafra concluída para el año 2010. Para este fin se analizaron las cifras oficiales de volúmenes de extracción de madera en concesiones castańeras y en concesiones madereras dentro de las Administraciones Técnicas de Tahuamanu (que administran las concesiones ubicadas en la provincia de Tahuamanu) y Tambopata-Manu (que administran las concesiones ubicadas en las provincias de Tambopata y Manu).

Se encontró que los volúmenes de madera extraídos son comparables y en algunos años hasta superiores a los extraídos en concesiones madereras. En particular, desde el 2004 al 2009, los volúmenes totales por hectárea por año extraídos de madera en concesiones castañeras varían desde $3.19 \mathrm{~m}^{3}$ hasta $3.81 \mathrm{~m}^{3}$ (sólo en el 2010 se extrajo en promedio $2.16 \mathrm{~m}^{3} / \mathrm{ha}$ ). En contraste, los volúmenes totales por hectárea por año extraídos de madera en concesiones de madera para el mismo período varían desde $1.05 \mathrm{~m}^{3}$ hasta $3.48 \mathrm{~m}^{3}$ (sólo en el 2010 se extrajo un promedio de $0.80 \mathrm{~m}^{3}$ / ha). En los años 2009 y 2010, el volumen total de madera aprovechado en concesiones castañeras superó al aprovechado de concesiones madereras. La gran mayoría de los contratos en concesiones castañeras reportaron volúmenes de madera aprovechados alrededor de los $5 \mathrm{~m}^{3} /$ ha mientras que la gran mayoría de los contratos de concesiones madereras reportó volúmenes mucho menores.

Con el objeto de adquirir información adicional sobre la viabilidad de la extracción de madera en las concesiones castañeras, se realizaron consultas a profesionales expertos. Algunos de ellos expresaron que no es viable extraer madera de las concesiones castañeras y que el límite numérico de intensidad de extracción no es suficiente ni pertinente aplicarlo como receta única para todas las concesiones castañeras. Las impresiones recogidas durante las entrevistas sugieren además que no ha ocurrido, como debió ser, la verificación o inspección ocular de los planes de manejo complementario anual antes (o después) del otorgamiento de los permisos de extracción de madera en concesiones castañeras.

El informe concluye que el carácter de complementariedad que actualmente permite extraer madera en concesiones castañeras en Madre de Dios se ha desvirtuado y en consecuencia, el objetivo inicial del establecimiento de estas concesiones. Se sugiere además que la aplicación de límites numéricos uniformes a las concesiones castañeras para la extracción de madera no es la forma adecuada de guiar el manejo de ambos productos. La eventual aplicación de un marco de manejo integrado de la madera y la castańa, enfocado más en buenas prácticas de aprovechamiento y menos en aspectos normativos poco flexibles, dependerá de la implementación de procesos de diálogo transparentes entre los diferentes actores de Madre de Dios y ajenos a visiones cortoplacistas o situaciones coyunturales. 



\section{Introducción}

En el Departamento de Madre de Dios (amazonia peruana), cuyos bosques albergan importantes recursos maderables además de servir de refugio de biodiversidad del país y del mundo, los productos forestales no maderables de mayor importancia económica son los frutos del árbol de la castaña (Bertholletia excelsa, Lecythidaceae) y el látex del árbol de la shiringa (Hevea brasiliensis, Euphorbiaceae). Tanto los frutos de la castańa como el látex de la shiringa han sido aprovechados comercialmente desde el siglo XIX y constituyen recursos forestales de subsistencia importantes de los cuales dependen muchas familias campesinas de la región, además que su exportación, particularmente de los frutos de la castaña, es una fuente de ingresos para el erario nacional (Figura 1).
El objetivo de este documento es evaluar la situación del aprovechamiento de madera en las concesiones castañeras de Madre de Dios desde el año 2004 cuando se publicó la norma que permitió esta actividad, así como evaluar el marco legal y el impacto que la política de extracción de madera ha generado en estas concesiones. El documento está dividido en seis secciones. La sección 2 describe el marco legal existente que regula el aprovechamiento de los recursos forestales no maderables con énfasis en la castańa. La sección 3 presenta el marco regulatorio del aprovechamiento de madera en las concesiones castañeras y el debate originado luego de que se emitiera la resolución No 294-2004-INRENA-IFFS, en el 2004, que autorizaba la extracción de hasta casi $5 \mathrm{~m}^{3} / \mathrm{ha}$ de madera en las mismas concesiones.

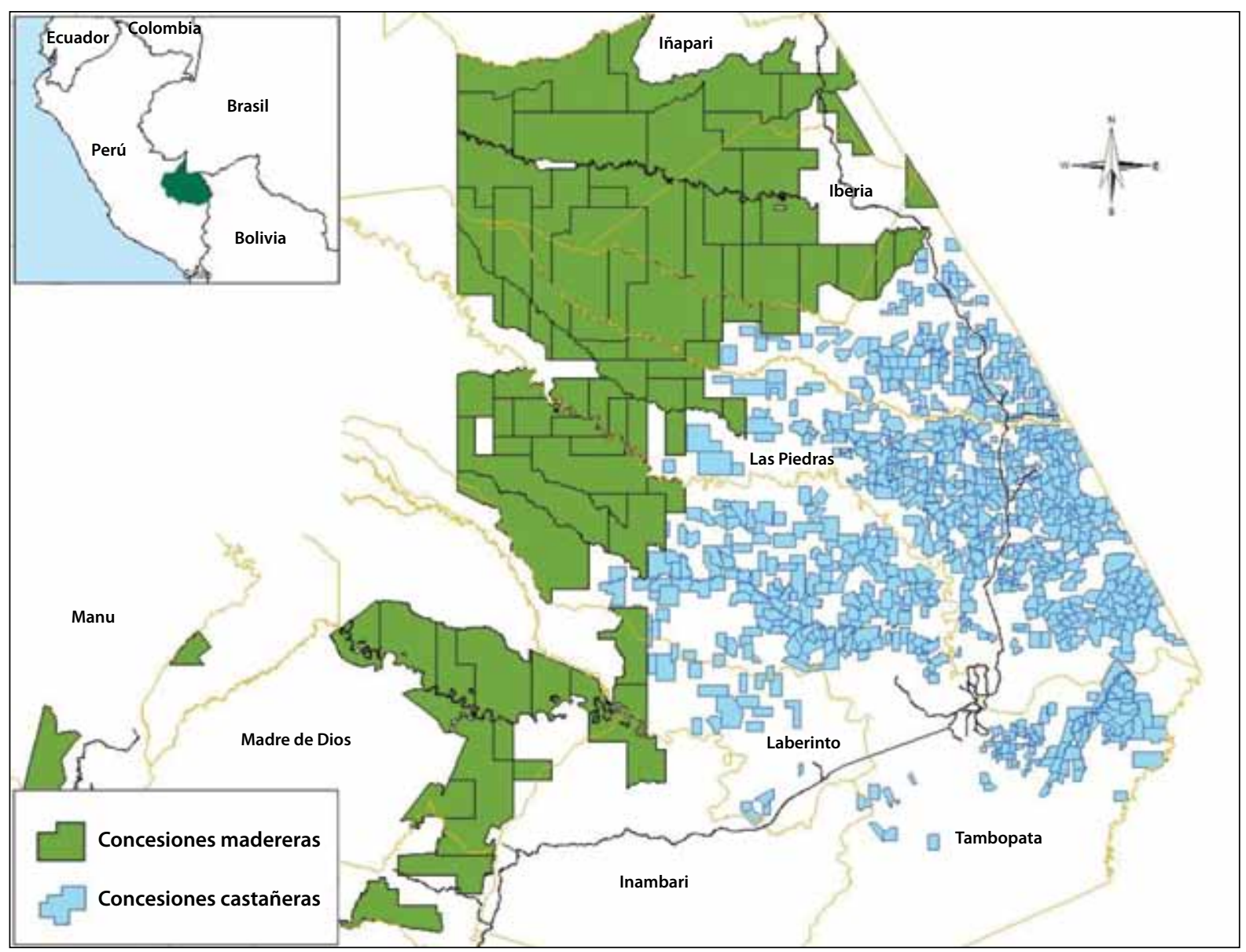

Figura 1. Distribución actual de las concesiones de castaña (Bertholletia excelsa) en el Departamento de Madre de Dios, Perú 
La sección 4 presenta un análisis de la información oficial acerca de los volúmenes de madera extraídos en las concesiones de castaña y en las concesiones maderables desde el 2004 hasta la última zafra completada en el 2010 con el fin de hacer una comparación de los volúmenes maderables extraídos en estos dos tipos de concesiones. La sección 5 presenta las percepciones de algunos expertos consultados sobre la viabilidad de extraer madera en las concesiones de castaña y la última sección presenta las conclusiones y recomendaciones. 


\section{Marco legal para el aprovechamiento de recursos forestales maderables y no maderables}

\section{Generalidades}

El marco legal actual que rige el sector forestal en el Perú está dado por la Ley Forestal y de Fauna Silvestre - LFFS (Ley $\left.\mathrm{N}^{\circ} 27308\right),{ }^{1}$ promulgada en el año 2000, y por su reglamento aprobado por Decreto Supremo No 014-2001-AG en el 2001. Esta Ley, en su artículo $10^{\circ}$, establece como modalidades de aprovechamiento y manejo de los recursos forestales en bosques naturales primarios (tierras públicas), las concesiones forestales con fines maderables y las concesiones forestales con fines no maderables. En el caso específico de las concesiones forestales con fines no maderables, hay dos modalidades: (1) concesiones para otros productos del bosque (e.g., castańa, shiringa, aguaje, palmito, lianas, resinas, gomas, plantas medicinales, ornamentales; crianzas de animales silvestres en ambiente natural y otros) y (2) concesiones para ecoturismo, conservación y servicios ambientales. Además de las concesiones forestales, se otorgan también permisos y autorizaciones forestales para el aprovechamiento de recursos forestales (madera, productos no maderables y fauna silvestre) en bosques de tierra de propiedad privada, bosques secundarios y en tierras de comunidades nativas y campesinas (LFFS, artículo $\left.11^{\circ}\right)$.

Todo aprovechamiento de los recursos forestales, con fines comerciales o industriales, requiere de la elaboración de un Plan de Manejo Forestal que debe ser aprobado por la autoridad respectiva. ${ }^{2}$ Este plan de manejo, el cual debe ser elaborado

1 El 27 de Junio del 2008, el Decreto Legislativo No 1090 aprobó la Ley Forestal y de Fauna Silvestre. Esta nueva ley fue aprobada en el marco de las facultades que fueron delegadas al Poder Ejecutivo por el Congreso de la República para legislar en diversos temas con el fin de implementar el Acuerdo de Promoción Comercial con los Estados Unidos. La ley tuvo muchos vacíos y fue sujeto de duras críticas. Debido a ello, se inició un proceso participativo de modificación de esta Ley. Así, en enero del 2009 se publicó la Ley N 29317 que modificó varios artículos del DL 1090, con lo cual se establecía un marco legal forestal más coherente que el por especialistas debidamente registrados, tiene dos niveles de planificación: (1) el plan general de manejo forestal (PGMF), que proporciona el marco general de planificación para el período de la concesión, y (2) el plan operativo anual (POA), que es el instrumento de planificación anual que incluye el inventario de aprovechamiento. Además, el aprovechamiento de los recursos forestales está sujeto al pago de un derecho de aprovechamiento a favor del Estado que se aplica, según la modalidad, por unidad de superficie, especie, volumen, o tamaño.

Hasta el 2008, todas las modalidades de aprovechamiento forestal (concesiones, permisos $\mathrm{y}$ autorizaciones) fueron otorgadas por el Instituto Nacional de Recursos Naturales (INRENA), un organismo público descentralizado del Ministerio de Agricultura. Sin embargo, en Diciembre de 2008 mediante el Decreto Supremo No 030-2008AG el INRENA fue absorbido por el Ministerio de Agricultura quien desde ese momento ejerció transitoriamente las funciones en materia forestal antes encargadas al INRENA mientras terminaba el proceso de transferencia de funciones a los gobiernos regionales (Peña 2010). En el caso de Madre de Dios, a partir de Abril del 2010 cuando se termina la transferencia de funciones en materia agraria del Ministerio de Agricultura al gobierno regional, este último empieza a ser el encargado del otorgamiento de concesiones forestales y la aprobación de los planes de manejo.

\footnotetext{
propuesto inicialmente. Posteriormente, también en enero del 2009, se publicó el Reglamento del DL 1090. Sin embargo, en junio del 2009 debido a masivas protestas indígenas en la Amazonía, el Congreso de la República derogó este nuevo marco legal y puso en vigencia nuevamente a la Ley Forestal y de Fauna Silvestre $N^{\circ} 27308$ (Peña 2010).

2 Hasta el 2008, el Instituto Nacional de Recursos Naturales (INRENA) fue la autoridad encargada de la aprobación de estos planes.
} 


\section{Establecimiento de concesiones forestales maderables y no maderables en Madre de Dios}

En Madre de Dios, la implementación de la LFFS $^{3}$, originó dos posiciones divergentes: (1) la de las organizaciones no gubernamentales (ONG) y algunos pequeños madereros que favorecían la implementación del sistema de concesiones y (2) la de algunas autoridades políticas locales, ligadas a élites madereras regionales y algunos pequeños madereros que se oponían a este sistema y querían mantener el status quo. A pesar de la oposición, en marzo del 2002 se llamó al primer concurso público para otorgar concesiones forestales con fines maderables y en abril del mismo año se otorgaron los primeros 56 contratos de concesiones. Este resultado generó malestar entre muchos pequeños madereros quienes quedaron excluidos de aprovechar los bosques de la región de manera legal y en junio del 2002, liderados por la Asociación de Extractores Forestales de Servicios y Comercialización de Madre de Dios, empezaron una huelga indefinida en Puerto Maldonado con el objeto de volver al régimen forestal anterior. ${ }^{4}$ A pesar de esto, en mayo del 2003 se llamó a un segundo concurso público; esta vez un mayor número de pequeños madereros se postularon. Así, en julio del 2003 se otorgaron 29 nuevos contratos de concesiones madereras en Madre de Dios (Cossío 2009).

Hacia fines del año 2002, se otorgaron las primeras concesiones castañeras. Dichas concesiones resultaron de la adecuación de la LFFS $\mathrm{N}^{\circ} 27308$ de los contratos anuales de 1,000 ha, de los contratos de más de dos años en áreas mayores a 1,000 ha y de los permisos para el aprovechamiento de castańa otorgados al amparo del Decreto Ley $\mathrm{N}^{\circ} 21147$. Es decir, al entrar en vigencia la LFFS $N^{\circ} 27308$, los titulares de los contratos de aprovechamiento de castaña tenían que adecuarse al nuevo régimen

3 La promulgación de esta ley obedeció a la necesidad de cambiar el régimen de sobre explotación, informalidad e ilegalidad al que los bosques peruanos habían estado sujetos durante las décadas de 1980 y 1990 (Cossío 2009).

4 El régimen forestal anterior (1975-2000), al amparo del Decreto Ley $\mathrm{N}^{\circ} 21147$, creó un sistema de sobre explotación de los bosques donde los grandes madereros contrataban a varios pequeños madereros para que soliciten los contratos de 1,000 ha que estaban destinados para ellos, y luego aprovechar mayores extensiones de bosques sin realizar un estudio técnico ni cumpliendo otras obligaciones requeridas para contratos de áreas mayores (Cossío 2009). de concesiones forestales si querían continuar realizando esta actividad, ya que la modalidad de aprovechamiento que realizaban no estaba contemplada en la nueva ley. Así, en el 2002 se promulgó el Decreto Supremo Nº36-2002-AG para regular los plazos y el procedimiento para la adecuación de los contratos a la nueva ley forestal y la entrega de contratos de concesión. ${ }^{5}$ Es preciso señalar que todo este proceso se llevó a cabo para los titulares de contratos para extracción de castaña otorgados bajo el amparo del Decreto Ley No 21147 y para los solicitantes de áreas que no habían sido otorgadas anteriormente (nuevos solicitantes). Para el primer caso, el titular del contrato debía presentar un expediente técnico con información básica del área: antecedentes, mapa de ubicación, memoria descriptiva, inventario y mapeo de árboles y debía demostrar que venía realizando aprovechamiento del recurso castaña en dicha área antes de la publicación de la norma. Con esta información, los profesionales del entonces INRENA deberían realizar inspecciones de campo en las que verificaban la presencia de árboles de castańa, caminos o estradas castañeras aperturadas y "limpias" así como la existencia de campamentos castańeros. En el caso de los nuevos solicitantes, se debía presentar el expediente técnico con información básica del área y la aprobación de la solicitud dependía en gran parte de la verificación de la existencia del recurso en el área solicitada, siempre que se tratara de un área no solicitada por otra persona.

\section{El aprovechamiento de castaña en concesiones castañeras}

En Madre de Dios, la castaña se encuentra distribuida en densidades arbóreas significativas a través de unos 2.5 millones de ha de bosques primarios (IIAP 2001). Las altas densidades han hecho que la actividad castańera sea de gran importancia económica y social para la región, beneficiando a aproximadamente 20,000 personas (casi el 25\% de la población), las cuales dependen directa e indirectamente de la actividad de recolección de las nueces. Así, la castaña puede llegar a contribuir hasta por la mitad de los ingresos anuales totales derivados del bosque

\footnotetext{
5 Para realizar esta adecuación, los poseedores de contratos de castańa debían presentar una propuesta técnica donde se señalaba el área que venían aprovechando y el número de árboles de castaña, incluyendo el inventario de los mismos.
} 
para muchas familias (Duchelle 2009). Además, por ser la cosecha de la castańa una actividad que causa una mínima perturbación al ecosistema, ésta es reconocida como una actividad que promueve la conservación del bosque amazónico (Arias 2010). Desde el 2004 a la fecha de publicación de este documento se han concedido 1,018 contratos de concesiones de castańa en tierras públicas (con un total de 886,939 ha) y 120 contratos en áreas protegidas $^{6}$ (con un total de 120,000 ha). La Figura 1 muestra la distribución espacial de las concesiones castañeras en Madre de Dios. El aprovechamiento de los frutos de la castańa se encuentra regulado por la LFFS N 27308 y su reglamento, además de normas complementarias. Sin embargo, ya desde el ańo 1981 hubo un reconocimiento de la importancia de la actividad castańera y el Estado declaró la veda indefinida para la quema y tala de árboles de castaña. ${ }^{7}$ Del mismo modo, en el año 2000, se declaró de interés nacional el aprovechamiento sostenible y la transformación con fines industriales y comerciales de la castaña (Peña 2010). En el Apéndice 1 se presenta una secuencia cronológica de las principales normas que fueron promulgadas para regular el aprovechamiento de la castańa.

Las concesiones castañeras se otorgan en exclusividad; es decir, no se pueden otorgar otros derechos forestales sobre la misma área a terceros (Peńa 2010). Estas concesiones se entregan en superficies de hasta 10,000 ha por 40 años renovables en bosques de producción permanente y en bosques en tierras de protección. El acceso a estas concesiones es a través de solicitudes presentadas por personas naturales o jurídicas. El interesado debe hacer pública la solicitud y en caso de no haber otros interesados en el área solicitada, dentro del plazo de 30 días calendario se procede al otorgamiento directo de la concesión. ${ }^{8}$ La autoridad competente tiene un plazo de 60 días calendario para aprobar la propuesta técnica y suscribir el contrato (de presentarse otros

6 Dirección General Forestal y de Fauna Silvestre, Junio 2010.

7 Resolución Ministerial No 00729-81-AG-DGFF.

8 Inicialmente, la Intendencia Forestal y de Fauna Silvestre (IFFS) de INRENA era la encargada de suscribir los contratos de concesión de castańa, pero desde enero del 2005 esta función fue delegada a las Administraciones Técnicas Forestales y de Fauna Silvestre (ATFFS) de Madre de Dios y las ATFFS de Tambopata-Manu y Tahuamanu con el fin de acelerar los procedimientos administrativos para el otorgamiento de estas concesiones. Desde Abril del 2009 esta función estuvo a cargo del Ministerio de Agricultura y desde Noviembre del 2010 el Gobierno Regional es el encargado. interesados en el área solicitada dentro del plazo establecido, una comisión ad hoc inicia un proceso de concurso público). En el contrato de concesión se establecen los derechos y obligaciones de las partes, las causales de caducidad de la concesión, así como las condiciones y limitaciones a las que está sujeta. El titular de la concesión tiene un plazo de seis meses para la presentación del plan de manejo. Los concesionarios tienen la obligación de presentar tanto el PGMF y el POA. ${ }^{9}$ La autoridad competente aprueba el plan de manejo dentro de los 60 días de su presentación y en caso de que la autoridad competente formule observaciones, el titular de la concesión tiene un plazo de 30 días para subsanarlos. Una vez el plan de manejo es aprobado, los concesionarios pueden empezar sus actividades. En Madre de Dios, el período de la zafra de castańa está comprendido entre el $1^{\circ}$ de noviembre hasta el 31 de octubre del ańo siguiente. ${ }^{10}$ Para la movilización de los productos extraídos, los concesionarios deben pagar el derecho de aprovechamiento.

\footnotetext{
9 La Resolución Jefatural No 224-2002-INRENA aprueba los términos de referencia para formular el PGMF y POA para el aprovechamiento de la castańa.

10 RJ No 006-2005-INRENA.
} 


\section{El aprovechamiento de madera en las concesiones castañeras}

En su artículo 31, la Ley Forestal y de Fauna Silvestre promueve el aprovechamiento sostenible de los recursos forestales con el fin de "conseguir la mayor rentabilidad económica y beneficio social a favor de la población vinculada a la actividad forestal". Debido a una interpretación de este principio, en el año 2002, a través del Decreto Supremo No 0442002-AG, se posibilitó el aprovechamiento comercial de madera en las concesiones forestales para otros productos del bosque. Para el aprovechamiento de madera, el adjudicatario de una concesión para otros productos del bosque debe incluir un Plan de Manejo Complementario Anual (PMCA) en el Plan General de Manejo Forestal (PGMF) presentado, luego de lo cual la autoridad competente otorgaría el permiso correspondiente (Recuadro 1). La Directiva No 014-2003-INRENA-IFFS define y uniformiza el procedimiento para el otorgamiento de permisos de aprovechamiento de madera en permisos o concesiones forestales de otros productos del bosque. El permitir el aprovechamiento de madera, en particular dentro de las concesiones castañeras, ha generado numerosas discusiones y cuestionamientos sobre la viabilidad y también pertinencia de esta actividad (Peña 2010). Las siguientes secciones presentan especificidades del marco regulatorio que propició la posibilidad de aprovechar madera en concesiones castañeras, los debates que se han dado en torno a la viabilidad técnica de esta norma y algunas percepciones sobre la misma.

\section{Dinámica regulatoria}

El Decreto Supremo No 044-2002-AG estableció la posibilidad de aprovechar madera "con carácter complementario" para fines comerciales o industriales en las concesiones forestales para otros productos del bosque. Este aprovechamiento está supeditado a aquellos casos en los que "el bosque tenga aptitud para extracción permanente de madera”, es decir donde "las condiciones físicas y ecológicas del lugar permitan técnicamente la extracción forestal maderable en forma sostenible". Con este fin, en abril del año 2003, la entonces Intendencia Forestal y de Fauna Silvestre (IFFS) estableció los procedimientos para el otorgamiento de permisos de aprovechamiento de madera en permisos o concesiones forestales de otros productos del bosque. Estos procedimientos están plasmados en la Directiva No 014-2003-INRENA-IFFS aprobada a través de la Resolución de Intendencia No 005-2003-INRENA.

Del mismo modo, el 29 de Setiembre del 2004, la Resolución de Intendencia No 294-2004-INRENAIFFS modificó la Directiva No 017-2003- INRENAIFFS $^{11}$ con el fin de adicionar los criterios para la autorización de volúmenes de madera en las concesiones de castańa hasta casi $5 \mathrm{~m}^{3} /$ ha. Bajo estos criterios, la autoridad regional es la responsable de realizar la inspección ocular, antes o después del otorgamiento del permiso correspondiente. La promulgación de la Resolución de Intendencia No 294-2004-INRENA-IFFS tuvo como respaldo el Informe Técnico No 052-2004-INRENA-ATFFSTAMB-MA/PNM-PDM, presentado por la ATFFS Tambopata-Manu el 24 de Septiembre del 2004, que propone un aprovechamiento máximo de $4.78 \mathrm{~m}^{3}$ de madera por hectárea dentro de una concesión de castaña (Recuadro 2).

Sin embargo, esta autorización sólo se mantuvo en vigencia hasta octubre del 2007 cuando fue derogada a través de la Resolución de Intendencia $\mathrm{N}^{\circ}$ 254-2007-INRENA-IFFS. El argumento para tomar dicha medida fue la carencia de indicadores que permitirían determinar el impacto negativo de la

11 La Directiva No 017-2003- INRENA-IFFS, aprobada por Resolución de Intendencia $\mathrm{N}^{\circ}$ 095-2003-INRENA-IFFS, regulaba la autorización de volúmenes de madera en los planes de manejo forestal en las concesiones forestales con fines maderables, permisos de aprovechamiento forestal en bosques en tierras de propiedad privada, comunidades nativas y campesinas, concesiones de forestación y/o reforestación, bosques locales y en los informes con carácter de declaración jurada de las concesiones forestales con fines maderables. 
Recuadro 1. Pasos administrativos en el aprovechamiento de madera en concesiones para otros productos del bosque

Para solicitar un permiso--Ser adjudicatario de un permiso o contrato de concesión para el manejo y aprovechamiento de productos forestales diferentes a la madera; (2) presentar una solicitud; (3) presentar una copia literal simple de la inscripción en los Registros Públicos y acreditar representación legal (en caso de ser una persona jurídica) o presentar documento de identidad; (4) presentar el PMCA firmado por un Ingeniero Forestal o personas jurídicas especializadas registradas con la autoridad competente; (5) adjuntar copia de la resolución que aprueba el PGMF y el POA.

Para otorgar un permiso--El personal de mesa de partes de las Administraciones Técnicas Forestales y de Fauna Silvestre (ATFFS) deberá: (1) orientar a los usuarios en la presentación de los expedientes; (2) recibir los expedientes y verificar los requisitos incluyendo obligaciones pendientes con la autoridad competente, expedidas por la ATFFS respectiva; (3) ingresar el expediente en el registro de solicitudes de otorgamiento de permisos correspondiente. Una vez recibida la solicitud, el procedimiento no podrá exceder 30 días hábiles de iniciado el trámite. Es imprescindible tener el PGMF y el POA aprobados del año zafra para el producto no maderable previo a la evaluación y/o aprobación del PMCA para el aprovechamiento de madera. Además es requisito del concesionario haber efectuado el censo forestal previo a la presentación del PMCA.

El expediente será evaluado por el responsable en la sede de la ATFFS quien deberá: (1) constatar que los requisitos estén conformes con las disposiciones establecidas; (2) remitir a la Intendencia Forestal y de Fauna Silvestre (IFFS) las coordenadas y el plano del área de la parcela de corta del PMCA cuando las ATFFS no cuenten con nodo CIEF (Centro Forestal Estadístico Forestal); (3) evaluar el PMCA, de acuerdo a los términos de referencia (aprobados por resolución jefatural $N^{\circ}$ 055-2003-INRENA); (4) poner en conocimiento del solicitante en caso de haber observaciones para que las absuelva en un plazo de 30 días; (4) realizar una inspección ocular cuando se encuentren inconsistencias en la evaluación del PMCA y los requisitos exigidos, previa notificación del interesado; (5) elaborar el informe técnico en el cual se concluirá si el caso es favorable o no, elevándolo a la ATFFS.

Para la resolución del procedimiento, el Administrador Técnico Forestal y de Fauna Silvestre deberá: (1) analizar el informe técnico y, en caso de encontrarlo conforme, suscribirlo a través de una resolución administrativa que aprueba el PMCA; (2) suscribir el permiso de aprovechamiento forestal por un año; (3) a partir del segundo año, renovar los permisos otorgados en los casos que: (i) después de evaluado el informe anual de actividades del PMCA concluido y el inventario inicialmente presentado quedaran saldos de madera aprovechable; (ii) al evaluar el PMCA para la zafra siguiente, estos guarden relación con los datos señalados en el PMCA anterior; (iii) de encontrarlos conforme, suscribir la resolución administrativa aprobando el POA correspondiente y otorgar el permiso respectivo.

Además, deberá: (4) remitir a la IFFS una copia de la resolución administrativa y el permiso de aprovechamiento forestal debidamente firmados; (5) en caso que el informe técnico sea desfavorable, (i) declarar denegada la solicitud a través de una resolución administrativa; (ii) emitir una resolución administrativa denegando la solicitud de permiso debido a que no se subsanaron las observaciones hechas al PMCA debidamente; (iii) emitir la resolución administrativa denegando la solicitud de permiso ya sea por presentar observaciones en el PMCA no subsanables o si el resultado de la inspección ocular es negativo.

tala selectiva sobre el recurso de la castaña, por lo cual "los márgenes de volúmenes que se puedan autorizar y los criterios para proceder a la autorización automática o, en su defecto, a la inspección ocular

12 Referido a que "la falta de certeza absoluta no debe utilizarse como razón para postergar la adopción de medidas eficaces y eficientes para evitar o mitigar anticipadamente dańos al ecosistema, amenaza de reducción importante o perdida de la diversidad biológica."

13 "La gestión ambiental tiene como objetivos prioritarios prevenir, vigilar y evitar la degradación ambiental y cuando no sea posible eliminar las causas que la generan, se deben adoptar las medidas de mitigación, recuperación, restauración o eventual compensación que correspondan." al amparo de la directiva mencionada no resultaban los más adecuados." En reconocimiento del principio precautorio ${ }^{12}$ y del principio de prevención ${ }^{13}$ de la Ley General del Ambiente, esta resolución dispone que las ATFFS realicen de forma obligatoria la inspección ocular previa a la aprobación del aprovechamiento de madera en las concesiones de castaña, así como la evaluación de los volúmenes que corresponde aprobarse para garantizar el origen legal de la madera solicitada y que el aprovechamiento de madera no perjudique la actividad principal (Peña 2010). 


\section{Recuadro 2. La propuesta original de extracción de madera en las concesiones castañeras}

Los principales argumentos presentados en 2004 en el informe técnico № 052-2004-INRENA-ATFFS-TAMB-MA/ PNM-PDM para proponer un volumen máximo de extracción de $4.78 \mathrm{~m} 3$ de madera por ha en concesiones castañeras fueron los siguientes:

- Las zonas de manejo de castaña asociadas con producción forestal permiten la extracción de madera con restricciones, por lo cual "es conveniente establecer un índice por hectárea en atención a las consideraciones ecológicas y de sostenibilidad de la especie".

- Se asume un promedio de 0.5 árboles de castaña/ha; al asignarse un radio de protección al árbol de castaña de $75 \mathrm{~m}$, se argumenta que en 100 ha los árboles de castaña ocuparían 88.31 ha y el área restante ( 11.69 ha) podría tener potencial para producción de madera.

- El potencial maderable de las terrazas medias de Madre de Dios es de $95 \mathrm{~m}^{3} / \mathrm{ha}$ del cual son aprovechables $40.93 \mathrm{~m}^{3} / \mathrm{h}$ a en base a la demanda de especies comerciales.

- Ya que 11.69 ha de un castañal tiene un potencial maderable de $40.93 \mathrm{~m}^{3} / \mathrm{ha}$, entonces en 1 ha de castañal se podría aprovechar un volumen máximo de $4.78 \mathrm{~m}^{3}$.

- En sectores donde la densidad de castaña es de 1.3 a 1.5 individuos /ha, el aprovechamiento de madera no sería posible en base a la fórmula aplicada y la aptitud de producción en estos sectores es esencialmente el recurso castaña.

- Será siempre necesaria la realización de inspecciones oculares en atención a las restricciones del impacto sobre el ecosistema del castañal.

Los argumentos técnicos asumen que la densidad de árboles de castaña es uniforme y que la distribución de la castaña es espacialmente regular, situación que no siempre se cumple. Por otro lado, la justificación de aplicar un radio de protección de $75 \mathrm{~m}$ alrededor de un árbol de castaña para reducir el área aprovechable para madera a un $11.69 \%$ del área del castañal no necesariamente implica que si existiese un árbol maderable al lado de uno de castaña este no se extraería.

\section{El debate sobre el aprovechamiento de madera en concesiones castañeras}

La promulgación de la Resolución de Intendencia No 294-2004-INRENA-IFFS en el 2004, que autorizaba la extracción de hasta $5 \mathrm{~m}^{3} /$ ha de madera en las concesiones de castańa, generó diferentes opiniones y reacciones por parte de los actores involucrados en la actividad en Madre de Dios; es decir los castañeros, autoridades gubernamentales, organizaciones no gubernamentales (ONG), el entonces INRENA, asesores y público en general.

En el caso de los castañeros, hubo dos grupos que lideraron diversas reuniones para discutir y mostrar su posición sobre la publicación de la resolución. El primer grupo liderado por la Federación de Castañeros de Madre de Dios (FEDECAMD), con la participación de castañeros de las principales localidades de producción de castaña a lo largo del

14 Este grupo mostró cautela al momento de hacer una crítica abierta a la RI No 294-2004-INRENA-IFFS. Se argumentó que esto se debió a que en septiembre del 2004 la FEDECAMD solicitó al Intendente Forestal, a través de un memorial, autorización para eje carretero Maldonado-Iberia (Planchón, Alegría y Mavila), tuvo una posición abierta de aceptar la esencia de la resolución que autoriza la extracción de madera en los castańales bajo el sustento de contar con ingresos adicionales para las familias castańeras; sin embargo no estuvieron de acuerdo con el volumen establecido. ${ }^{14} \mathrm{El}$ segundo grupo liderado por la Asociación de Castañeros de Madre de Dios (ASECAMD), con la participación de castañeros de las zonas del Río Pariamanu, Las Piedras, Laberinto y de la Reserva Nacional Tambopata, tuvo diferentes posiciones. Los castañeros de Pariamanu y Las Piedras estaban de acuerdo con la extracción de madera en las concesiones castañeras pero no con el volumen establecido, mientras que los castañeros de la reserva

el aprovechamiento de madera en los castańales a fin de poder capitalizarse y enfrentar los gastos de la elaboración de los planes de manejo. En este memorial (firmado por ocho bases de asociaciones de castańeros y 10 representantes) se solicitaba la autorización para la extracción de madera; mas no se mencionaba el volumen a extraer. Sin embargo, durante una de las reuniones de esta federación se solicitó de manera verbal un volumen de madera de hasta 70.75 $\mathrm{m}^{3}$ por castañal para el período de un año. Este procedimiento creó discrepancias entre los líderes castañeros que firmaron dicho memorial y condujo a la división en grupos para enfrentar este impase. 
estaban en desacuerdo total con la posibilidad de la extracción de madera dado que al encontrarse dentro de la Reserva Nacional Tambopata, la limitación para aprovechar madera de los castañales se mantendría (G. Martínez, comunicación personal).

Igualmente, dentro del entonces INRENA, se generaron posiciones encontradas luego de la promulgación de esta resolución. Así, en Octubre del 2004 la Administración de Control Forestal y de Fauna Silvestre del INRENA presentó el Informe No 737-2004-INRENA-IFFS-DACFFS proveyendo en el mismo una opinión técnica en respuesta a la resolución (No 052-2004-INRENA-ATFFSTAMB-MA/PNM-PDM) presentada por la ATFFS Tambopata-Manu y que sirvió de sustento para la elaboración de la resolución. Este informe especifica que el cálculo del volumen máximo de madera aprovechable en castañales de $4.78 \mathrm{~m}^{3} /$ ha es un valor ideal ya que asume que la extracción de madera no causaría dańos colaterales a la masa forestal remanente incluyendo, de manera particular, daños a los árboles de castaña circundantes al árbol maderable a cosechar. El mismo informe también provee de argumentos en contra del volumen máximo de madera a extraer de las concesiones castañeras ya que éste valor se compararía con el volumen por hectárea que usualmente se extrae de concesiones madereras. De tal forma, la extracción de madera en concesiones de castaña no sería realmente una actividad complementaria como tal y de tal modo, la autorización de extraer $5 \mathrm{~m}^{3} /$ ha de madera en concesiones de castaña podría generar descontento entre los concesionarios madereros debido a que éstos han tenido que cumplir con muchos requisitos administrativos y fiscales que los concesionarios de castaña no han tenido que seguir. Finalmente, este informe recomendaba la modificación de la RI No 294-2004-INRENA-IFFS a fin de que se considerara un límite superior de hasta $1 \mathrm{~m}^{3} / \mathrm{ha}$ de volumen de madera a ser extraído de las concesiones castañeras. Este valor se determinó en base a la aplicación de coeficientes de impacto del aprovechamiento de madera sobre el rodal remanente. Sin embargo, el informe no fue tomado en consideración y la RI No 294-2004-INRENA-IFFS siguió en vigencia. A pesar que en octubre del 2007 se derogó esta resolución, en la práctica se sigue aplicando. 


\section{La dinámica del aprovechamiento de madera en concesiones castañeras y en concesiones madereras entre 2004 y 2010}

Con el objeto de obtener un estimado cuantitativo y fortalecer el debate sobre cómo ha evolucionado la extracción de madera en las concesiones castañeras de Madre de Dios, en esta sección se presenta un análisis de los volúmenes oficiales de madera extraídos en las concesiones castañeras desde el año 2004 (cuando se permitió la extracción de madera) hasta la última zafra completada en los registros (Octubre 2010). Adicionalmente se presenta el análisis de los volúmenes oficiales de extracción de madera que ha ocurrido en las concesiones madereras, para el mismo período, con el objeto de hacer una comparación entre ambos tipos de concesiones. Estos análisis se han desarrollado tomando los datos de volúmenes y áreas de la base de datos de los contratos de concesiones de castańa y de madera.

\section{Dinámica de la extracción de madera en las concesiones castañeras}

La madera es un recurso natural de gran importancia económica en Madre de Dios. El tipo de especies y los volúmenes en las concesiones forestales determinan la escala y la intensidad de la extracción. Se evaluó la cantidad de madera extraída por año en cifras oficiales en las concesiones castañeras teniendo en cuenta la ubicación de estas concesiones dentro de las Administraciones Técnicas de Tahuamanu (que administra las concesiones ubicadas en la provincia de Tahuamanu) y Tambopata-Manu (que administra las concesiones ubicadas en las provincias de Tambopata y Manu). En el Apéndice 2 se muestra los totales de madera extraída según las cifras oficiales con sus respectivas áreas y número de contratos autorizados por año en las áreas que conforman cada Administración Técnica ${ }^{15}$ (ATFFS).

15 A través de todo el informe, "extracción" o "madera extraída" siempre se refiere a cifras oficiales provenientes de las ATFFS respectivas.
La extracción de madera en las concesiones de castaña habría aumentado a través de los ańos, particularmente hasta el 2008 (Figura 2). Ha ocurrido mayor extracción de madera de las concesiones castañeras en las provincias de Tambopata y Manu que en la provincia de Tahuamanu; esto se ha debido principalmente al mayor número de concesiones castañeras otorgadas en estas dos provincias. Así, desde el 2004 al 2009 se ha extraído en la concesiones castañeras de Madre de Dios un promedio que va desde 3.19 hasta $3.81 \mathrm{~m}^{3}$ de madera por hectárea por año; sólo en el 2010 se extrajo en promedio $2.16 \mathrm{~m}^{3}$ de madera por hectárea en la región (Apéndice 2).

\section{Dinámica de la extracción de madera en las concesiones madereras}

La actividad maderera es una de las actividades económicas de mayor importancia en Madre de Dios empleando a casi el 65\% de la población económicamente activa. Tradicionalmente, las tres especies comerciales más extraídas son Swietenia macrophylla (caoba), Cedrela odorata (cedro) y Cedrelinga catenaeformis (tornillo), las que representan casi el 60\% del volumen total extraído en la región (Chirinos \& Ruíz 2003) aunque en los últimos años nuevas especies han ganado ubicación en el mercado (Cossío 2009). En el Apéndice 3 se muestran los totales de madera extraída por hectárea, con sus respectivas áreas y número de contratos autorizados por año en las áreas que conforman cada Administración Técnica (ATFFS) desde el 2004.

Según cifras oficiales, se habrían extraído mayores volúmenes de madera por hectárea en las provincias de Tambopata y Manu que en la provincia de Tahuamanu (Figura 3), a pesar de la mayor área otorgada en Tahuamanu. Esto puede ser un reflejo de la existencia de especies poco conocidas 


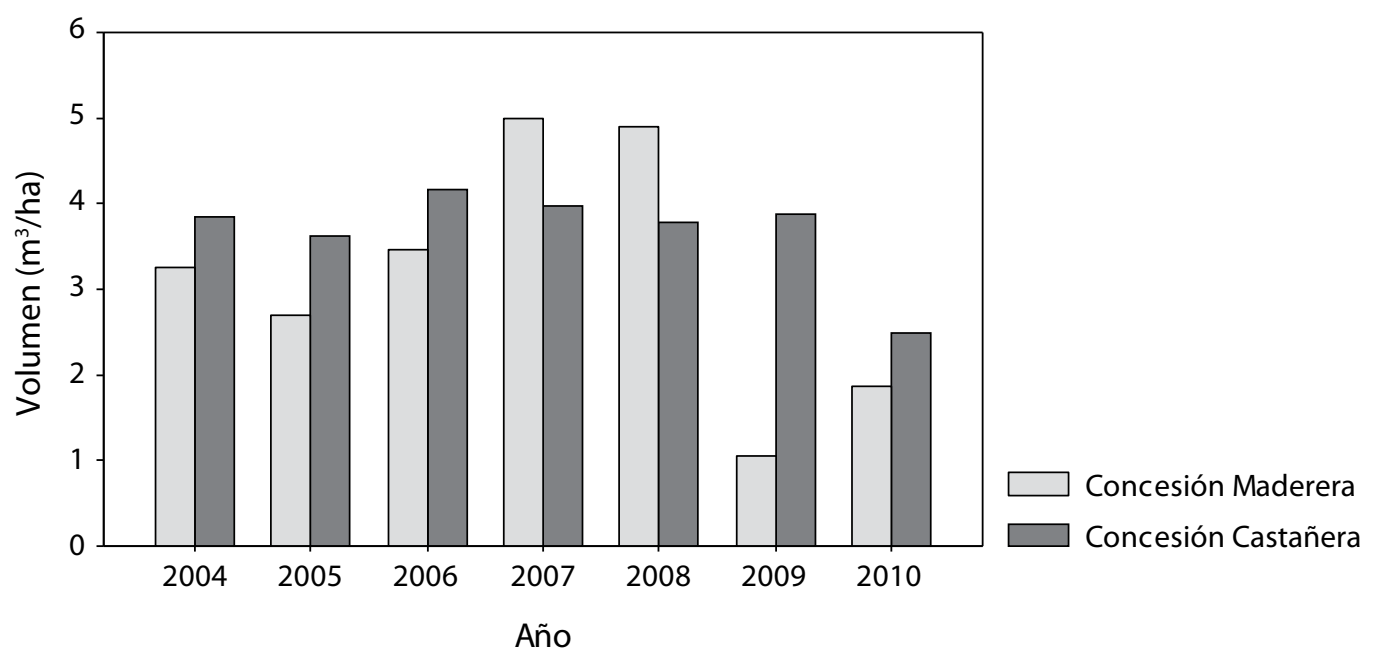

Figura 2. Volúmenes oficiales extraídos de madera por hectárea por año en concesiones castañeras y concesiones madereras en Madre de Dios (combinando los volúmenes por hectárea reportados en los contratos en las ATFFS de Tahuamanu y Tambopata-Manu) entre 2004 y 2010. Las barras oscuras corresponden a los volúmenes por hectárea reportados en los contratos en concesiones de castaña analizados para un mismo año (ver Apéndice 2) y las barras claras a los volúmenes reportados en los contratos en concesiones de madera analizados para un mismo año (ver Apéndice 3).

y de poco valor comercial en las provincias de Tambopata y Manu (en donde la caoba ha sido sobre-explotada). De tal forma, mayores volúmenes extraídos compensarían financieramente los costos de extracción. Sin embargo, a pesar que el principal objetivo de estas concesiones es el aprovechamiento de madera, los volúmenes promedio por hectárea extraídos por concesión maderera son generalmente menores a los extraídos en las concesiones castañeras (Figuras 2 y 3). Así tenemos que desde el 2004 al 2009 se ha extraído en Madre de Dios promedios que van desde $1.05 \mathrm{~m}^{3}$ hasta $3.48 \mathrm{~m}^{3}$ de madera por hectárea por año en concesiones madereras. En el 2010 se extrajo un promedio de $0.80 \mathrm{~m}^{3} / \mathrm{ha}$ (Apéndice 3). Al graficar la distribución de frecuencia de volúmenes por hectárea de madera extraída según cifras oficiales en concesiones madereras y concesiones castañeras en función del número de contratos de extracción analizados, se observa claramente que existe un mayor número de contratos en concesiones castańeras reportando mayores volúmenes cosechados de madera por hectárea con respecto a aquellos provenientes de concesiones madereras; y que además, la gran mayoría de los contratos de concesiones castañeras cosecharon cantidades alrededor del límite numérico de $5 \mathrm{~m}^{3} /$ ha mientras que para las concesiones madereras este valor fue considerablemente menor (Figura 4). Esto podría sugerir que no necesariamente los volúmenes extraídos según cifras oficiales en las concesiones castañeras provienen de esos mismos sitios.

En general, la extracción de madera en las concesiones madereras ha disminuido a partir del año 2007 (la Figura 5 presenta volúmenes totales). Una de las principales causas de esta disminución es que desde 2007 (cinco años desde el otorgamiento de las concesiones maderables en el 2002), se tiene la obligación de elaborar un plan de manejo quinquenal para poder continuar con el manejo de la concesión forestal. Este plan de manejo implica la elaboración de un inventario forestal exploratorio de toda la concesión y debido a la limitada capacidad financiera de la mayoría de los concesionarios de madera ha sido imposible para muchos continuar con sus actividades de aprovechamiento. Muchos concesionarios forestales no han podido pagar sus derechos de aprovechamiento de madera según la legislación existente debido a los efectos de la crisis económica mundial; además existe el efecto de una mayor supervisión por parte de la Oficina Supervisora de las Concesiones Forestales (OSINFOR). 

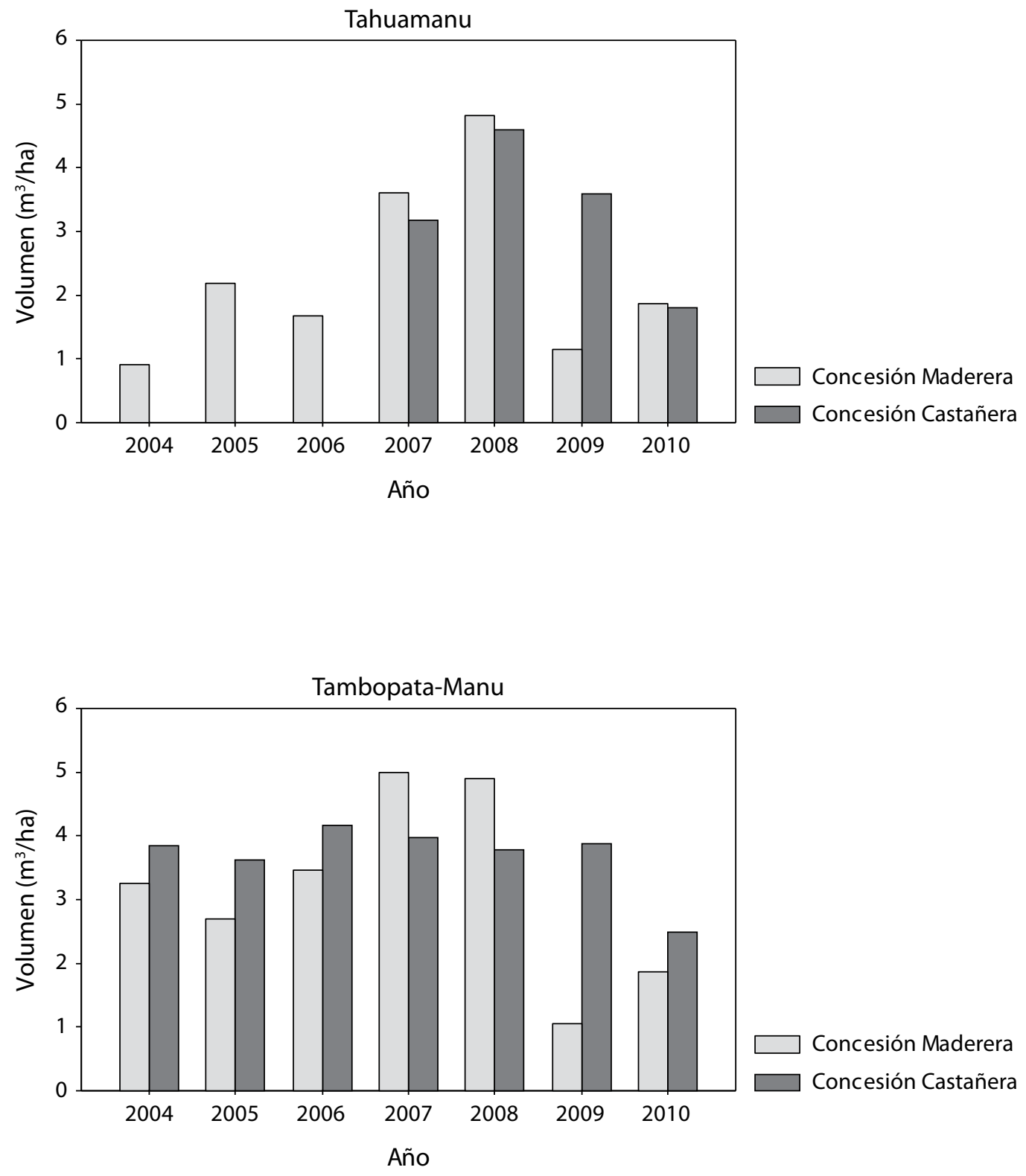

Figura 3. Volúmenes extraídos de madera por hectárea por año en concesiones de castaña y concesiones de madera reportados oficialmente en las ATFFS de Tahuamanu y Tambopata-Manu entre 2004 y 2010. Las barras oscuras corresponden a los volúmenes por hectárea reportados oficialmente en los contratos en concesiones de castaña analizados para un mismo año (Apéndice 2) y las barras claras a los volúmenes reportados oficialmente en los contratos en concesiones de madera analizados para un mismo año (Apéndice 3). 

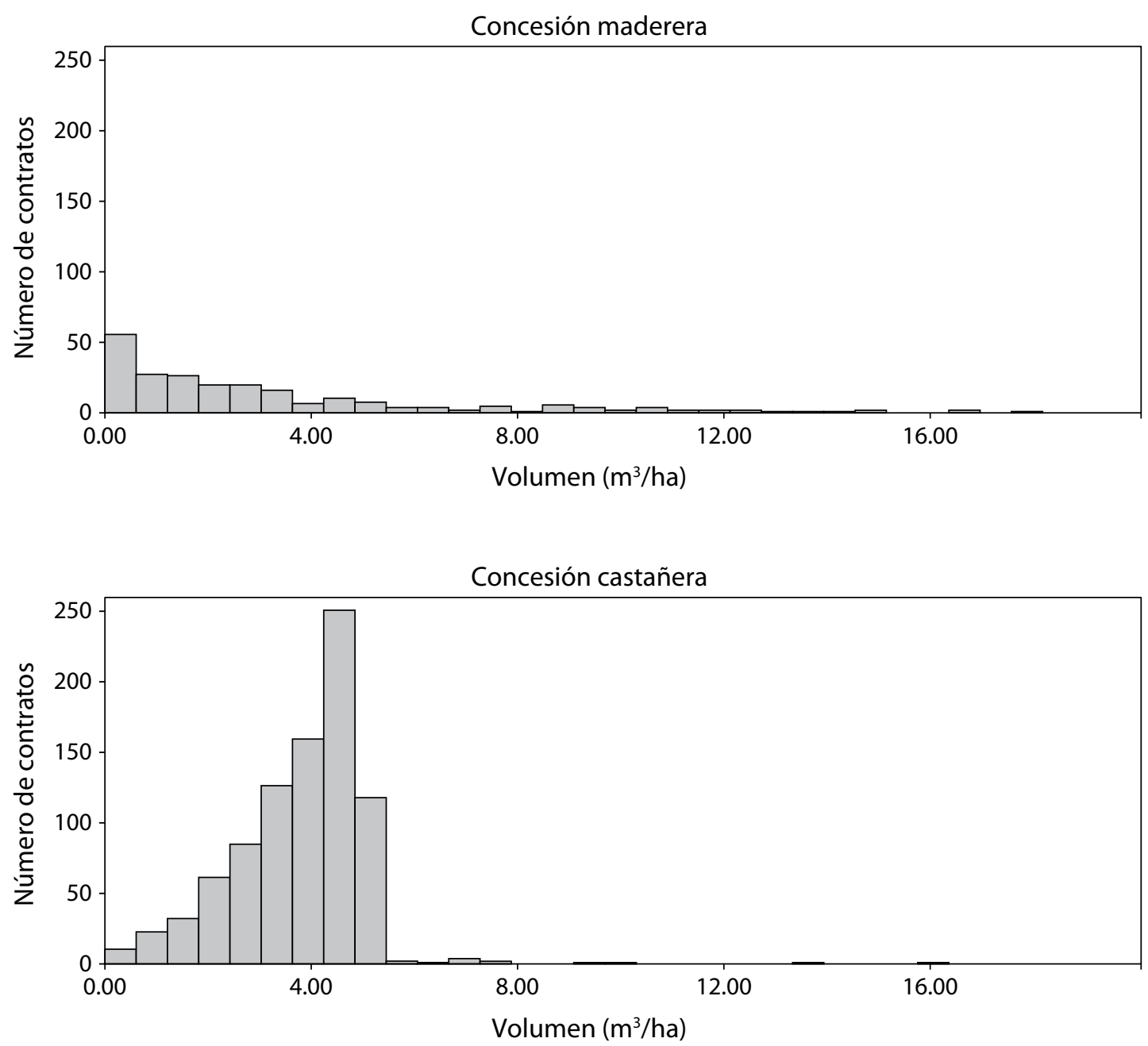

Figura 4. Distribución de frecuencia de volúmenes por hectárea de madera extraída según cifras oficiales en concesiones madereras y concesiones castañeras en Madre de Dios entre 2004 y 2010 en función del número de contratos de extracción. Un mayor número de contratos en concesiones castañeras reportan mayores volúmenes cosechados de madera por hectárea que aquellos provenientes de concesiones madereras y la gran mayoría de los contratos en concesiones castañeras cosecharon cantidades alrededor de $5 \mathrm{~m}^{3} / \mathrm{ha}$ mientras que para las concesiones madereras este valor fue substancialmente menor.

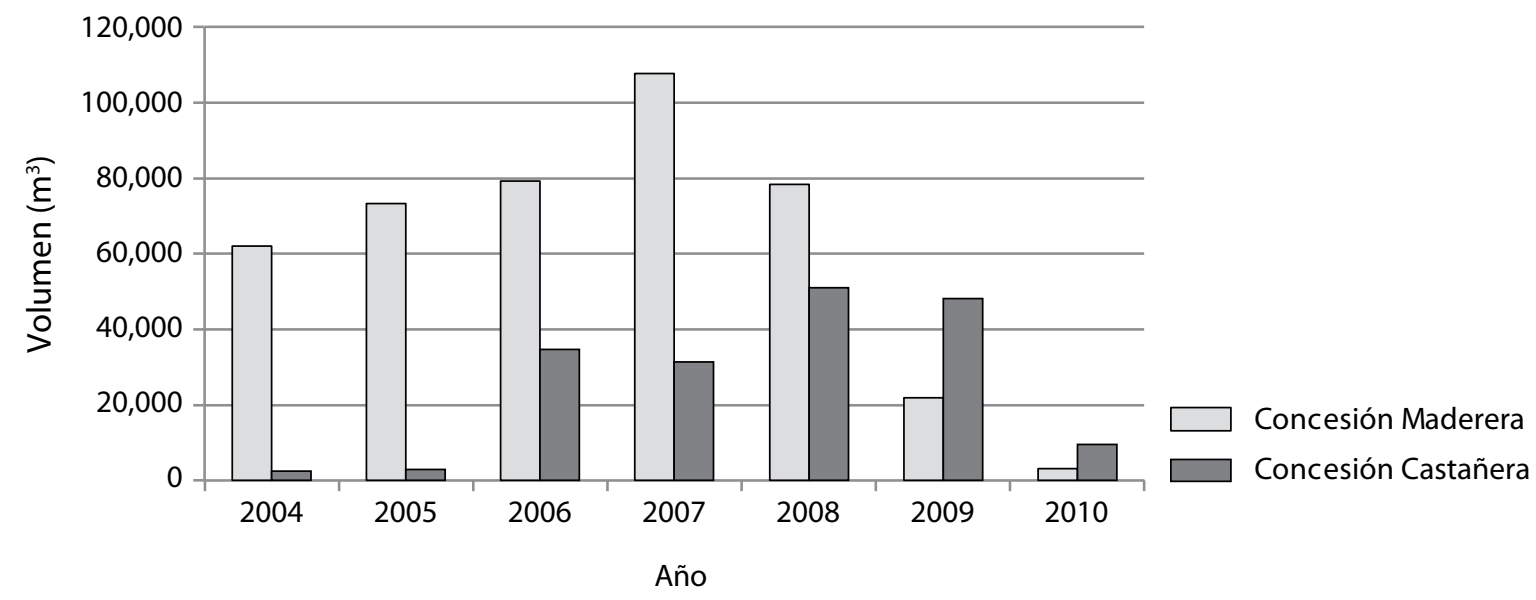

Figura 5. Volúmenes totales de madera extraídos según cifras oficiales en concesiones madereras y castañeras entre 2004 y 2010 en Madre de Dios (combinando los valores reportados oficialmente en los contratos en las ATFFS de Tahuamanu y Tambopata-Manu). 


\section{Percepciones sobre la viabilidad de la extracción de madera en concesiones castañeras}

Con el objeto de adquirir conocimiento sobre la viabilidad técnica de la extracción de madera en las concesiones de castaña, en Octubre y Noviembre de 2010 se realizó una consulta informal mediante entrevistas presenciales a profesionales expertos en las ciudades de Puerto Maldonado y Lima. Los temas considerados fueron: (1) la viabilidad técnica de la extracción de madera en las concesiones de castańa; (2) la intensidad de extracción como criterio y criterios alternativos y (3) la identificación de problemas en el marco legal y su aplicación. La información presentada a continuación refleja una síntesis de las opiniones obtenidas durante las entrevistas.

\section{Viabilidad técnica}

Algunos expertos manifestaron que no es viable extraer madera de las concesiones castañeras. En su opinión, la extracción de madera, con todas las operaciones que implica (apertura de caminos, vías de arrastre, patio de acopio, generación de claros de tala), no es realmente una actividad complementaria a la recolección de castaña (como lo sería la recolección de otros productos no maderables del bosque o el ecoturismo). Para otros expertos, la viabilidad de aprovechar madera de las concesiones castañeras depende de varios factores tales como las especies maderables a extraer y estiman que de ninguna manera se debería autorizar la extracción de madera en aquellos sitios donde hay bajo potencial o no hay recurso maderero. De la misma forma, consideran que se deberían tener en cuenta las especies maderables a extraer ya que algunas aparentan tener una relación simbiótica con el árbol de castaña a nivel de sus polinizadores. También expresaron que sería contraproducente efectuar la extracción de madera en lugares donde la densidad de los árboles de castańa es alta. Otra apreciación fue que el castañero casi siempre estará sujeto a la imposición de la voluntad de terceros que sólo se dedican a la extracción de madera y no al manejo y por lo tanto son víctimas directas de las consecuencias de la tala sin planificación y con beneficios económicos mínimos.

\section{La intensidad de la extracción de madera como criterio numérico}

Para uno de los expertos entrevistados, un límite numérico superior de la intensidad de extracción de madera por hectárea ayudaría a la toma de decisiones sobre el aprovechamiento. Sin embargo, para la mayoría de los expertos entrevistados un límite numérico per se no es suficiente y es hasta contraproducente. Por ejemplo, variables como la capacidad productiva de árboles de castańa en función de su proximidad a especies maderables de tamaño cosechable podrían ser útiles ya que hay castañales que tienen árboles que ya dejaron de producir o que tienen baja producción anual (ver un ejemplo para Acre, Brasil, en Kainer et al. 2007). O por otro lado, deben cuidarse de recibir daños ocasionados por la tala selectiva de madera si es que son árboles de castaña de carácter productivo. Como se menciona arriba, otras variables a considerar son el potencial maderable a largo plazo dentro de los castańales (el cual es variable), el tipo de aprovechamiento a utilizar (artesanal o mecanizado) y la frecuencia de extracción. Aplicar un criterio numérico común para todas las concesiones de castaña desestima además las capacidades técnicas de los concesionarios castañeros que son muy heterogéneas, sin mencionar la variabilidad biofísica que existe entre las concesiones. En resumen, un mensaje transmitido por varios expertos durante las entrevistas es que la elaboración de criterios para permitir la extracción de madera en las concesiones castañeras deben integrar ambas actividades.

Algunos expertos perciben además que la extracción de madera en castañales podría afectar la polinización de la castańa. Se sabe que un individuo adulto 
de castaña necesita polen de otro individuo para producir frutos; si no hay polinización cruzada, no hay producción (Mori y Prance 1990). La polinización de la flor del árbol de castaña la realizan abejorros de los géneros Xylocopa, Bombus, Eulaema y Centris (Motta 2002). Estos insectos también polinizan otros árboles de la misma familia de la castaña como las especies maderables del género Couratari, comúnmente conocidas como "misa", y las que en los últimos años han ganado gran demanda en el mercado de Madre de Dios (aunque es posible que otras especies maderables alberguen a estos polinizadores). Sin embargo, la biología de los polinizadores y su relación directa con la productividad de la castańa son muy poco conocidas en estos ambientes y los expertos reconocen que no hay información suficiente para guiar el manejo.

\section{Aplicación del marco legal sobre el aprovechamiento madera en las concesiones castañeras}

Algunos de los expertos consideran que la norma emitida en la resolución RI No 294-2004-INRENAIFFS sobre la autorización de extraer madera en concesiones castañeras fue implementada debido a una situación coyuntural en la provincia de Tambopata y no en base a aspectos técnicos sustentados. En ese momento había problemas socioeconómicos fuertes en Tambopata ya que muchos madereros se quedaron sin áreas de aprovechamiento al no acceder a una concesión forestal por concurso público; además, la limitada capacidad financiera de los castañeros les imposibilitaba la elaboración de los PGMF y POA, los cuales eran obligatorios para realizar el aprovechamiento de la castańa. Ante esta situación, la ATFFS Tambopata-Manu y un congresista de la región propusieron como solución a este problema la extracción de madera de los castañales para subsidiar a los castañeros con la venta de madera y así poder elaborar sus planes de manejo y, al mismo tiempo, beneficiar a los madereros los que podrían trabajar haciendo la extracción en estas áreas.

Las impresiones recogidas durante las entrevistas sugieren que no ocurrió, como debió ser, la verificación ocular de los PMCA durante el otorgamiento de los permisos de extracción de madera en concesiones de castańa. Esto se ha debido principalmente a la falta de capacidad de las ATFFS de Madre de Dios, las cuales no cuentan con recursos suficientes para efectuar verificaciones de campo e implementar un sistema de monitoreo de las áreas castañeras. Los volúmenes a extraer, la ubicación de la parcela de corta en función del ordenamiento castañero y la existencia de las especies maderables solicitadas dentro de la parcela de corta quedan a discreción de la respectiva ATFFS, quien evalúa el PMCA y quien debería hacer una inspección ocular antes de cualquier aprobación. Esto se resume en la percepción de uno de los expertos entrevistados:

Cuando se dio esta norma, la gente empezó a solicitar la aprobación de sus planes complementarios con los árboles ubicados en todo lado y esto se iba a acabar en menos de un año; entonces lo que se hizo fue sacar una resolución jefatural que por lo menos tratara de mitigar esta extracción... esta resolución establecía que no se podía extraer madera a un radio de $40 \mathrm{~m}$ alrededor de los árboles de castaña; sin embargo, esta resolución también se dio sin ningún sustento técnico.

Los expertos coinciden que la extracción de madera pasó a ser la actividad principal (no la secundaria) en los castańales. Las impresiones recogidas durante las entrevistas indican además que se ha facilitado la tala ilegal (debido al alto volumen máximo permitido) a través del "blanqueo" o la legalización de madera de procedencia ilegal a través de la venta de las guías forestales emitidas para concesiones castañeras. Esto se refleja muy bien en la Figura 4 la cual indica que la gran mayoría de los contratos de cosecha de madera en concesiones castañeras se centraron en el valor de $5 \mathrm{~m}^{3} /$ ha mientras que en el caso de las concesiones madereras, la gran mayoría de los contratos de cosecha de madera en volúmenes por hectárea tienen valores considerablemente menores.

En opinión de algunos expertos existe actualmente un vacío legal, ya que a pesar de que se ha anulado la resolución RI No 294-2004-INRENA-IFFS, no hay ningún reglamento que impida actualmente la extracción de cualquier volumen de madera en concesiones castañeras y ".. lo único que hay es que se puede otorgar un plan complementario en una concesión de castaña". Finalmente, se ha propiciado la "venta" de los castañales. En algunos casos, el castañal vale más por la madera que tiene que por la castańa que se ha extraído y lo que está ocurriendo es la transferencia del castañal para fines madereros y no para fines castañeros. 


\section{Conclusiones y recomendaciones}

1. La inmensa mayoría de los contratos analizados en concesiones castańeras reportaron volúmenes cosechados centrados alrededor del límite teórico de $5 \mathrm{~m}^{3} / \mathrm{ha}$ mientras que para los contratos de concesiones de madera, la inmensa mayoría de los contratos analizados reportó volúmenes cosechados mucho menores. Aunque no es posible discernir si los volúmenes de extracción de madera en castañales, reportados en este estudio a través de las cifras oficiales de las ATFFS del Programa Regional de Manejo de Recursos Forestales y de Fauna Silvestre de Madre de Dios, fueron realmente cosechados en el lugar donde fueron aprobados, o si en realidad la madera fue extraída en otras áreas, la cosecha de madera en concesiones castañeras ha conducido a una explotación de este recurso en la región bajo mínima fiscalización. El carácter de complementariedad de extraer madera en concesiones castañeras en Madre de Dios se ha desvirtuado.

2. Los volúmenes de extracción de madera en concesiones castańeras son comparables y en algunos ańos hasta superiores, a los extraídos en concesiones madereras. Según datos oficiales, desde el 2004 al 2009, los volúmenes promedio extraídos de madera en concesiones castañeras varían desde $3.19 \mathrm{~m}^{3}$ hasta $3.81 \mathrm{~m}^{3}$ por hectárea por año (sólo en el 2010 se extrajo en promedio $2.16 \mathrm{~m}^{3}$ por hectárea). En contraste, los volúmenes promedio extraídos de madera en concesiones madereras en el mismo período varían desde $1.05 \mathrm{~m}^{3}$ hasta $3.48 \mathrm{~m}^{3}$ por hectárea por ańo (sólo en el 2010 se extrajo un promedio de $0.80 \mathrm{~m}^{3}$ por ha).

3. La extracción de madera en concesiones castańeras en Madre de Dios continúa con poco sustento legal o técnico. La prescripción de límites numéricos de manera uniforme no ha contribuido a promover el carácter complementario de esta actividad y, por sí solos, estos límites no son suficientes para tal fin. Existe la percepción de que la extracción de madera afecta la producción de frutos de castaña. No es posible confirmar científicamente si esta percepción es cierta o no, y de ser cierta, si el efecto operaría a corto, mediano o largo plazo. Se necesita investigación rigurosa en función de diferentes intensidades y sistemas de extracción de madera. Minimizar el impacto de la tala de madera sobre los árboles de castaña sería esencial en presencia de tal incertidumbre. ${ }^{16}$

4. Es necesario racionalizar el marco normativo e institucional referente a las concesiones castañeras, incluyendo una revisión de la cantidad de normas y la multiplicidad de entidades públicas encargadas de hacer cumplir tales normas, promover la implementación de las mismas y vigilar que éstas contribuyan como una opción idónea de desarrollo con bosques en pie. Un siguiente paso sería sistematizar las reglas de juego y promover su internalización por parte de los diferentes actores castañeros (concesionarios, asesores, tomadores de decisión, compradores) para que puedan aportar en la mejora de dicho marco. Un proceso amplio de información y difusión de las constataciones establecidas en el presente informe podría ayudar a cumplir este objetivo.

5. Promover un manejo "integrado", más que “complementario", entre la madera y la castaña, es una opción a debatir entre los diferentes actores de Madre de Dios. Y más que enfocarse en lo normativo, es necesario propiciar un diálogo para establecer de forma participativa

16 Un estudio de percepciones con el método de fortalezas, oportunidades, debilidades y amenazas (FODA) combinado con un riguroso análisis cuantitativo (analytic hierarchy process) realizado en 2009 por CIFOR en la región Madre de Dios-AcrePando (MAP) arrojó que, en Madre de Dios, la principal amenaza identificada por cuatro diferentes grupos de actores entrevistados fue el daño ocasionado a los castañales por la extracción de madera con poco o ningún control (Duchelle et al. en imprenta). 
un conjunto de buenas prácticas que consideren entre otros aspectos, el potencial maderable de cada concesión castañera, la ubicación espacial de los árboles maderables dentro de ésta y la aplicación de técnicas de tala dirigida para minimizar los daños a la masa forestal remanente. Además, simplificar la legislación forestal y adecuarla a un manejo integrado de ambos productos, teniendo en cuenta las percepciones y decisiones de los castañeros en permitir o no la extracción de madera en sus castañales así como su capacidad de manejar el bosque. La eventual aplicación de un marco de manejo integrado, enfocado más en buenas prácticas y menos en normas poco flexibles, dependerá en gran parte de la implementación de procesos de diálogo transparentes y ajenos a visiones cortoplacistas o situaciones coyunturales. 


\section{Referencias}

Arias, E. 2010 Valoración económico-ecológica de los bosques húmedos de la Amazonia sud-occidental, Perú: estudio de caso Madre de Dios. Tesis doctoral, Universidad Nacional Autónoma de México-Universidad Nacional Agraria La Molina, Ciudad de México, México, y Lima, Perú.

Chirinos, C. y Ruíz, M. 2003 Desarrollo e implementación de lineamientos de control de la extracción ilegal para un manejo forestal sostenible en el Perú. Sociedad Peruana de Derecho Ambiental, Organización Internacional de las Maderas Tropicales, Lima, Perú.

Cossío, R. 2009 Capacity for timber management among private small-medium forest enterprises in Madre de Dios, Peru. Tesis doctoral, University of Florida, Gainesville, FL, EUA.

Duchelle, A.E. 2009 Conservation and livelihood development in Brazil nut producing communities in a tri-national amazonian frontier. Tesis doctoral, University of Florida, Gainesville, FL, USA.

Duchelle, A.E., Guariguata, M.R., Less, G., Albornoz, M.A., Chavez, A. y Melo, T. [En imprenta] Evaluating the opportunities and barriers to multiple use of Brazil nuts and timber in Western Amazonia. Forest Ecology and Management.

IIAP 2001 Madre de Dios camino al desarrollo sostenible: propuesta de zonificación económica ecológica como base para el ordenamiento territorial. Instituto de Investigaciones de la Amazonia Peruana (IIAP), Lima, Perú.

Kainer, K.A., Wadt, L.H.O. y Staudhammer, C.L. 2007 Explaining variation in Brazil nut fruit production. Forest Ecology and Management 250: 244-255.

Motta Maues, M. 2002 Reproductive phenology and pollination of the Brazil nut tree (Bertholletia excelsa Humb. \& Bonpl. Lecythidaceae) in eastern Amazonia. En: Kevan, P. e Imperatriz Fonseca, V.L. (eds.), Pollinating bees: the conservation link between agriculture and nature. Ministerio del Medio Ambiente, Brasilia, Brasil.

Mori, S.A. y Prance, G.T. 1990 Taxonomy, ecology, and economic botany of the Brazil nut (Bertholletia excelsa Humb. \& Bonpl.: Lecythidaceae). Advances in Economic Botany 8: 130-150.

Peña, P. 2010 La castaña y la shiringa en Madre de Dios: análisis del marco legal y propuestas participativas para su mejora. Cuaderno de Investigación No 3. Sociedad Peruana de Derecho Ambiental, Lima, Perú.

SPDA 2008 Guía legal: castańa, shiringa, agroforestería e incendios forestales. Sociedad Peruana de Derecho Ambiental (SPDA), Lima, Perú. 


\section{Apéndices}

Apéndice 1. Normas que regulan la actividad castañera

\begin{tabular}{|c|c|c|}
\hline Norma & Fecha & Descripción \\
\hline RI No 254-2007-INRENA-IFFS & $17 / 10 / 2007$ & $\begin{array}{l}\text { Deroga la RI No 095-2003-INRENA-IFFS a través de la cual se aprobó } \\
\text { la Directiva No 017-2003-INRENA-IFFS y su modificatoria. Establece la } \\
\text { realización de una inspección ocular previa a la aprobación del PMCA } \\
\text { para el aprovechamiento de recursos maderables en concesiones o } \\
\text { permisos de castaña }\end{array}$ \\
\hline RJ No 331-2006-INRENA & $22 / 12 / 2006$ & $\begin{array}{l}\text { Establece la obligatoriedad de realizar inspecciones oculares en áreas que } \\
\text { incluyen el aprovechamiento de caoba }\end{array}$ \\
\hline RJ No 096-2006-INRENA & $17 / 04 / 2006$ & $\begin{array}{l}\text { Establece pautas para la ampliación de plazos para la movilización de } \\
\text { saldos de productos forestales y para el reingreso a las parcelas de corta } \\
\text { anual }\end{array}$ \\
\hline RI No 072-2005-INRENA-IFFS & $12 / 04 / 2005$ & $\begin{array}{l}\text { Delega a las ATFFS de Tambopata-Manu y Tahuamanu, la responsabilidad } \\
\text { de aprobar el PGMF y los POA de los contratos de concesión de castaña } \\
\text { de Madre de Dios }\end{array}$ \\
\hline RJ No 012-2005-INRENA & $13 / 01 / 2005$ & $\begin{array}{l}\text { Delega a las ATFFS de Tambopata-Manu y Tahuamanu, la responsabilidad } \\
\text { de suscribir contratos de concesión de castaña }\end{array}$ \\
\hline RJ No 006-2005-INRENA & $12 / 01 / 2005$ & $\begin{array}{l}\text { Establece el período de la zafra para las concesiones de castaña en Madre } \\
\text { de Dios }\end{array}$ \\
\hline RI No 294-2004-INRENA-IFFS & $29 / 09 / 2004$ & $\begin{array}{l}\text { Adiciona a la Directiva № 017-2003-INRENA-IFFS los criterios para la } \\
\text { autorización de volúmenes de madera en las concesiones de castaña }\end{array}$ \\
\hline RJ No 033-2004-INRENA-IFFS & $23 / 02 / 2004$ & $\begin{array}{l}\text { Modifica el formato del contrato de concesión para el manejo y } \\
\text { aprovechamiento de productos forestales diferentes a la madera }\end{array}$ \\
\hline RJ No 023-2004-INRENA & $09 / 02 / 2004$ & $\begin{array}{l}\text { Delega a la Intendencia Forestal y de Fauna Silvestre (IFFS), la } \\
\text { responsabilidad de suscribir contratos de concesión forestal con fines } \\
\text { maderables, no maderables y de forestación y reforestación. Delega } \\
\text { a la Administración Técnica Forestal y de Fauna Silvestre (ATFFS) de } \\
\text { Tambopata-Manu, la responsabilidad de suscribir contratos de concesión } \\
\text { de castaña en Madre de Dios }\end{array}$ \\
\hline RJ No 146-2003-INRENA & 07/10/2003 & $\begin{array}{l}\text { Modifica el formato del contrato de concesión para el manejo y } \\
\text { aprovechamiento de productos forestales diferentes a la madera }\end{array}$ \\
\hline RJ No 055-2003-INRENA & $28 / 04 / 2003$ & $\begin{array}{l}\text { Aprueba los TdR para formular el Plan de Manejo Complementario Anual } \\
\text { (PMCA) para el aprovechamiento de madera en concesiones o permisos } \\
\text { de castaña }\end{array}$ \\
\hline RI No 005-2003-INRENA & $16 / 04 / 2003$ & $\begin{array}{l}\text { Aprueba la Directiva No 014-2003-INRENA-IFFS para el otorgamiento de } \\
\text { permisos de aprovechamiento de madera en permisos o concesiones } \\
\text { forestales con fines no maderables para otros productos del bosque }\end{array}$ \\
\hline RS No 010-2003-AG & $27 / 03 / 2003$ & $\begin{array}{l}\text { Aprueba valor del derecho de aprovechamiento de productos forestales } \\
\text { diferentes a la madera }\end{array}$ \\
\hline RJ No 280-2002-INRENA & $26 / 07 / 2002$ & $\begin{array}{l}\text { Aprueba el formato de la Guía de Transporte Forestal para productos al } \\
\text { estado natural para los titulares de los contratos de concesión }\end{array}$ \\
\hline RJ No 259-2002-INRENA & $11 / 07 / 2002$ & $\begin{array}{l}\text { Aprueba el formato de contrato de concesión para manejo y } \\
\text { aprovechamiento de productos forestales diferentes a la madera }\end{array}$ \\
\hline RJ No 224-2002-INRENA & $26 / 06 / 2002$ & $\begin{array}{l}\text { Aprueba los Términos de Referencia (TdR) para la formulación del PGMF y } \\
\text { del POA para el aprovechamiento de castaña }\end{array}$ \\
\hline DS No 044-2002-AG & $11 / 06 / 2002$ & $\begin{array}{l}\text { Establece precisiones para el aprovechamiento de madera en las } \\
\text { concesiones forestales con fines no maderables. Se prohíbe la tala y } \\
\text { quema de árboles de castaña }\end{array}$ \\
\hline
\end{tabular}




\begin{tabular}{|c|c|c|}
\hline Norma & Fecha & Descripción \\
\hline DS No 052-2001-AG & $24 / 10 / 2001$ & $\begin{array}{l}\text { Declaran prioridad y autorizan atención de solicitudes presentadas por } \\
\text { las comunidades nativas de selva y ceja de selva para el aprovechamiento } \\
\text { de recursos forestales en sus tierras }\end{array}$ \\
\hline DS No 014-2001-AG & 06/04/2001 & $\begin{array}{l}\text { Reglamento de LFFS. Los artículos y capítulos relacionados al } \\
\text { aprovechamiento de recursos forestales no maderables son Art. 3.3, 3.73; } \\
\text { Título V, Capítulos I, II, III, V, Vl; Título XII: Art. } 363,365,366,367 \text { y } 369 \text {. }\end{array}$ \\
\hline Ley № 27308 & $15 / 07 / 2000$ & $\begin{array}{l}\text { Ley Forestal y de Fauna Silvestre (LFFS). El artículo 10, inciso } 2 \text { establece } \\
\text { como una modalidad de aprovechamiento forestal las concesiones } \\
\text { forestales con fines no maderables. Art. 11, permisos y autorizaciones } \\
\text { forestales; Art. 12, aprovechamiento forestal en tierras de comunidades } \\
\text { nativas/campesinas; Art. 15, manejo forestal; Art. 18, causales de } \\
\text { caducidad; Art. 19, derecho de aprovechamiento }\end{array}$ \\
\hline DS No 014-2000-AG & $05 / 05 / 2000$ & $\begin{array}{l}\text { Declara de interés nacional el aprovechamiento y la transformación con } \\
\text { fines industriales y comerciales de la castaña }\end{array}$ \\
\hline RD № 030-97-MA-DSRA-MD-RI & 26/05/1997 & $\begin{array}{l}\text { Prohíbe la corta de árboles de castaña y el otorgamiento de títulos de } \\
\text { propiedad en áreas forestales donde se encuentre la castaña y la shiringa }\end{array}$ \\
\hline RM № 00729-81-AG-DGFF & $11 / 08 / 1981$ & $\begin{array}{l}\text { Declara en veda por tiempo indefinido la tala y quema de árboles de } \\
\text { castaña }\end{array}$ \\
\hline
\end{tabular}

Fuente: Modificado de SPDA (2008). RM: Resolución Ministerial; RD: Resolución Directoral; DS: Decreto Supremo; RJ: Resolución Jefatural; RI: Resolución de Intendencia 


\begin{abstract}
Apéndice 2. Volúmenes totales de madera extraídos por hectárea por año en las concesiones castañeras reportados oficialmente en las Administraciones Técnicas de Tahuamanu y Tambopata-Manu. Se presenta también el total para Madre de Dios.
\end{abstract}

\begin{tabular}{|c|c|c|c|c|c|}
\hline Año zafra & & $\begin{array}{l}\text { Área total de } \\
\text { extracción (ha) }\end{array}$ & $\begin{array}{l}\text { Volumen total } \\
\text { extraído }\left(\mathrm{m}^{3}\right)\end{array}$ & $\begin{array}{l}\text { Volumen extraído } \\
\left.\text { por área ( } \mathrm{m}^{3} / \mathrm{ha}\right)\end{array}$ & $\begin{array}{l}\mathrm{N}^{\circ} \text { contratos } \\
\text { analizados }\end{array}$ \\
\hline \multirow[t]{3}{*}{2004} & Tahuamanu & 0 & 0 & 0 & 0 \\
\hline & Tambopata-Manu & 736 & 2,543 & 3.46 & 5 \\
\hline & Madre de Dios & 736 & 2,543 & 3.46 & 5 \\
\hline \multirow[t]{3}{*}{2005} & Tahuamanu & 0 & 0 & 0 & 0 \\
\hline & Tambopata-Manu & 886 & 2,823 & 3.19 & 11 \\
\hline & Madre de Dios & 886 & 2,823 & 3.19 & 11 \\
\hline \multirow[t]{3}{*}{2006} & Tahuamanu & 0 & 0 & 0 & 0 \\
\hline & Tambopata-Manu & 9,099 & 34,650 & 3.81 & 147 \\
\hline & Madre de Dios & 9,099 & 34,650 & 3.81 & 147 \\
\hline \multirow[t]{3}{*}{2007} & Tahuamanu & 93 & 329 & 3.55 & 2 \\
\hline & Tambopata-Manu & 8,174 & 31,123 & 3.81 & 154 \\
\hline & Madre de Dios & 8,267 & 31,453 & 3.80 & 156 \\
\hline \multirow[t]{3}{*}{2008} & Tahuamanu & 3,082 & 10,538 & 3.42 & 48 \\
\hline & Tambopata-Manu & 11,457 & 40,550 & 3.54 & 228 \\
\hline & Madre de Dios & 14,540 & 51,087 & 3.51 & 276 \\
\hline \multirow[t]{3}{*}{2009} & Tahuamanu & 1,481 & 4,654 & 3.14 & 21 \\
\hline & Tambopata-Manu & 11,447 & 43,435 & 3.79 & 192 \\
\hline & Madre de Dios & 12,927 & 48,089 & 3.72 & 213 \\
\hline \multirow[t]{3}{*}{2010} & Tahuamanu & 1,193 & 1,928 & 1.62 & 15 \\
\hline & Tambopata-Manu & 3,267 & 7,702 & 2.36 & 52 \\
\hline & Madre de Dios & 4,460 & 9,630 & 2.16 & 67 \\
\hline
\end{tabular}

Fuente: Administración Técnica Forestal y de Fauna Silvestre de Tambopata-Manu y Tahuamanu. Datos obtenidos en Octubre 2010. Estos datos corresponden a las zafras terminadas. La última zafra terminada o último período de aprovechamiento fue el año 2010. No siempre se consideraron todos los contratos presentes en la ATFFS debido a que en algunos casos las áreas de los POA mostraron el área total del castañal en lugar del área en donde se hizo la extracción en ese año. No se pudo verificar en el campo por lo cual se excluyeron del análisis. El número de contratos totales para Madre de Dios en cada año fue: $2004=6 ; 2005=11 ; 2006=150 ; 2007=157 ; 2008=285 ; 2009=218 ; 2010=84$. 
Apéndice 3. Volúmenes totales de madera extraídos por año en las concesiones madereras reportados oficialmente en las Administraciones Técnicas de Tahuamanu y Tambopata-Manu. Se presenta también el total para Madre de Dios.

\begin{tabular}{|c|c|c|c|c|c|}
\hline Año zafra & & $\begin{array}{l}\text { Área total de } \\
\text { extracción (ha) }\end{array}$ & $\begin{array}{l}\text { Volumen total } \\
\text { extraído }\left(\mathrm{m}^{3}\right)\end{array}$ & $\begin{array}{l}\text { Volumen extraído } \\
\text { por área }\left(\mathrm{m}^{3} / \mathrm{ha}\right)\end{array}$ & $\mathrm{N}^{\circ}$ contratos \\
\hline \multirow[t]{3}{*}{2004} & Tahuamanu & 29,162 & 20,209 & 0.69 & 16 \\
\hline & Tambopata-Manu & 11,131 & 41,767 & 3.75 & 18 \\
\hline & Madre de Dios & 40,293 & 61,976 & 1.54 & 34 \\
\hline \multirow[t]{3}{*}{2005} & Tahuamanu & 22,271 & 35,374 & 1.59 & 24 \\
\hline & Tambopata-Manu & 13,355 & 37,832 & 2.83 & 30 \\
\hline & Madre de Dios & 35,626 & 73,206 & 2.05 & 54 \\
\hline \multirow[t]{3}{*}{2006} & Tahuamanu & 24,706 & 27,302 & 1.11 & 22 \\
\hline & Tambopata-Manu & 10,510 & 51,856 & 4.93 & 26 \\
\hline & Madre de Dios & 35,216 & 79,158 & 2.25 & 48 \\
\hline \multirow[t]{3}{*}{2007} & Tahuamanu & 21,427 & 60,563 & 2.83 & 18 \\
\hline & Tambopata-Manu & 9,536 & 47,227 & 4.95 & 22 \\
\hline & Madre de Dios & 30,963 & 107,790 & 3.48 & 40 \\
\hline \multirow[t]{3}{*}{2008} & Tahuamanu & 20,714 & 55,546 & 2.68 & 18 \\
\hline & Tambopata-Manu & 6,069 & 22,913 & 3.78 & 15 \\
\hline & Madre de Dios & 26,783 & 78,458 & 2.93 & 33 \\
\hline \multirow[t]{3}{*}{2009} & Tahuamanu & 19,350 & 21,089 & 1.09 & 11 \\
\hline & Tambopata-Manu & 1,653 & 879 & 0.53 & 3 \\
\hline & Madre de Dios & 21,004 & 21,968 & 1.05 & 14 \\
\hline \multirow[t]{3}{*}{2010} & Tahuamanu & 4,005 & 3,223 & 0.80 & 4 \\
\hline & Tambopata-Manu & 0 & 0 & 0 & 0 \\
\hline & Madre de Dios & 4,005 & 3,223 & 0.80 & 4 \\
\hline
\end{tabular}

Fuente: Administración Técnica Forestal y de Fauna Silvestre de Tambopata-Manu y Tahuamanu. Datos obtenidos en Octubre 2010. Estos datos corresponden a las zafras terminadas. La última zafra terminada o último período de aprovechamiento fue el año 2010. El número de contratos en la ATFFS y el número de contratos analizados fue el mismo. 


\section{Apéndice 4. Volúmenes promedio de madera extraídos por hectárea por año reportados oficialmente en las} concesiones castañeras de Tahuamanu.

\begin{tabular}{|c|c|c|c|c|c|}
\hline Nombre científico & Nombre común & 2007 & 2008 & 2009 & 2010 \\
\hline Amburana cearensis & Ishpingo & 0 & 0.35 & 0.34 & 0.10 \\
\hline Aniba roseadora & Moena rosada & 0 & 0.13 & 0 & 0 \\
\hline Aniba sp. & Moena & 0.24 & 0.40 & 0.67 & 0.20 \\
\hline Aspidosperma macrocarpon & Pumaquiro & 0.20 & 0.48 & 0.27 & 0.22 \\
\hline Aspidosperma subincanum & Quillobordon & 0.13 & 0 & 0 & 0 \\
\hline Brosimum alicastrum / B. uleanum & Manchinga & 0 & 1.00 & 0 & 0 \\
\hline Cedrela odorata & Cedro & 0.09 & 0.52 & 0 & 0 \\
\hline Cedrelinga catenaeformis & Tornillo & 2.03 & 2.72 & 3.31 & 2.23 \\
\hline Chorisia integrifolia & Lupuna & 0 & 1.29 & 0.96 & 0.32 \\
\hline Copaifera reticulata & Copaiba & 0 & 0.38 & 0.38 & 0 \\
\hline Coumarouna odorata & Shihuahuaco & 0.41 & 1.80 & 1.13 & 1.33 \\
\hline Couratari guianensis & Misa & 0 & 0.74 & 0 & 0.21 \\
\hline Couratarisp. & Misa & 0 & 1.42 & 0 & 0 \\
\hline Dipteryx micrantha & Shihuahuaco & 0 & 0 & 2.01 & 0 \\
\hline Erythroxylum catuaba & Catuaba & 0.58 & 0.73 & 0.78 & 0.40 \\
\hline Guarea trichiloides & Requia & 0 & 0 & 0 & 0.49 \\
\hline Hymenaea oblongifolia & Yutubanco & 0 & 0.29 & 0 & 0 \\
\hline Hymenaea sp. & Azucar huayo & 0 & 0.32 & 0.27 & 0.14 \\
\hline Laureaceae sp. & Palta morena & 0 & 0.17 & 0.08 & 0 \\
\hline Macheaerium sp. & Palo baston & 0 & 0.19 & 0 & 0 \\
\hline Matisia sp. & Sapote & 0 & 0.80 & 0 & 0.25 \\
\hline Myroxylon balsamun & Estoraque & 0.07 & 0.34 & 0 & 0 \\
\hline Schizolobium sp. & Pashaco & 0.53 & 1.27 & 0.94 & 0.52 \\
\hline Tabebuia sp. & Tahuari & 0 & 0.18 & 0.03 & 0 \\
\hline Vochysia sp. & Catuaba & 0 & 0 & 1.09 & 0 \\
\hline
\end{tabular}


Apéndice 5. Volúmenes promedio de madera extraídos por hectárea por año reportados oficialmente en las concesiones castañeras de Tambopata-Manu.

\begin{tabular}{|c|c|c|c|c|c|c|c|c|}
\hline Nombre científico & Nombre común & 2004 & 2005 & 2006 & 2007 & 2008 & 2009 & 2010 \\
\hline Amburana cearensis & Ishpingo & 0.26 & 0 & 0.50 & 0.26 & 0.35 & 0.24 & 0 \\
\hline Aniba roseadora & Moena rosada & 0 & 0 & 0 & 0 & 0 & 0.16 & 0 \\
\hline Aniba sp. & Moena & 0.37 & 0.65 & 0.83 & 0.93 & 0.90 & 1.02 & 0.87 \\
\hline Aspidosperma macrocarpon & Pumaquiro & 0.42 & 0.43 & 0.93 & 0.68 & 0.65 & 0.79 & 0.44 \\
\hline Aspidosperma subincanum & Quillobordon & 0 & 0 & 0.25 & 0.16 & 0.08 & 0.30 & 0 \\
\hline Brosimum alicastrum / B. uleanum & Manchinga & 0 & 0 & 0 & 0 & 0.19 & 0 & 0 \\
\hline Calophyllum brasiliense & Lagarto caspi & 0 & 0 & 0.56 & 0.37 & 0.15 & 0 & 0 \\
\hline Cedrela odorata & Cedro & 0.61 & 0.79 & 1.06 & 0.55 & 0.47 & 0.60 & 0.63 \\
\hline Cedrelinga catenaeformis & Tornillo & 3.83 & 2.19 & 1.74 & 2.27 & 2.33 & 2.73 & 1.84 \\
\hline Ceiba pentandra & Huimba & 0 & 0 & 0 & 0 & 0.38 & 0 & 0 \\
\hline Chorisia integrifolia & Lupuna & 0.36 & 0 & 0.51 & 0.84 & 1.20 & 1.01 & 1.70 \\
\hline Chorisia sp. & Lupuna & 0 & 0 & 0 & 2.61 & 0 & 0 & 0 \\
\hline Copaifera reticulata & Copaiba & 0.41 & 0 & 0.20 & 0.36 & 0.30 & 0.07 & 0 \\
\hline Couratari guianensis & Misa & 0 & 0.37 & 0.41 & 0.43 & 0.64 & 0.55 & 0.48 \\
\hline Couratari sp. & Misa & 0 & 0 & 0 & 1.15 & 0.32 & 0 & 0 \\
\hline Dipteryx sp. & Shihuahuaco & 0 & 0 & 0.49 & 0.43 & 0.80 & 1.43 & 1.89 \\
\hline Dipteryx odorata & Shihuahuaco & 0.26 & 0.65 & 0.58 & 0 & 0 & 0 & 0 \\
\hline Erythroxylum catuaba & Catuaba & 0 & 0 & 0.74 & 0.57 & 0.69 & 0.30 & 0.84 \\
\hline Eschweilera sp. & Misa & 0 & 0 & 0 & 0.68 & 0.04 & 0 & 0 \\
\hline Eschweilera timbuchensis & Misa colorada & 0 & 0 & 0 & 0 & 0 & 0 & 0.36 \\
\hline Guarea trichiloides & Requia & 0 & 0 & 0 & 0.05 & 0.26 & 0.15 & 0 \\
\hline Huberodendron swietenoides & Achihua & 0 & 0 & 0 & 0.31 & 0.59 & 0.40 & 0 \\
\hline Hura crepitans & Catahua & 0 & 0.13 & 0 & 0 & 0 & 0 & 0 \\
\hline Hymenaea courbaril & Azucar huayo & 0 & 0 & 0 & 0 & 0.45 & 0 & 0 \\
\hline Hymenaea oblongifolia & Yutubanco & 0 & 0 & 0 & 0.48 & 0 & 0 & 0 \\
\hline Hymenaea sp. & Azucar huayo & 0 & 0.34 & 0.60 & 0.73 & 0.51 & 0.46 & 0 \\
\hline Jacaranda copaia & Achihua & 0 & 0 & 0 & 0 & 0.22 & 0 & 0 \\
\hline Laureaceae sp. & Palta morena & 0 & 0 & 0 & 1.06 & 0.53 & 0.74 & 0.64 \\
\hline Matisia cordata / Capparis angulata & Sapote & 0 & 0 & 0 & 0 & 1.08 & 0.75 & 0.42 \\
\hline Myroxylon balsamun & Estoraque & 0.32 & 0.11 & 0.51 & 0.64 & 0.31 & 0 & 0 \\
\hline Ocotea sp. & Moena & 0 & 0 & 0 & 0 & 1.41 & 0 & 0 \\
\hline Pithecelobium sp. & Pashaco colorado & 0 & 0 & 0 & 0 & 0.26 & 0 & 0 \\
\hline "Por identificar 7" & Aleton & 0 & 0 & 0 & 0 & 0.43 & 0 & 0 \\
\hline Schizolobium amazonicum & Pino chuncho & 0 & 0 & 0.45 & 0.77 & 0.52 & 0 & 0 \\
\hline Schizolobium sp. & Pashaco & 0.33 & 0.24 & 0.95 & 0.81 & 0.73 & 0.84 & 0.88 \\
\hline Sickingia tinctorea & Guacamayo caspi & 0 & 0 & 0 & 0 & 0 & 0.17 & 0 \\
\hline Swietenia macrophylla & Caoba & 0.09 & 0.66 & 0.80 & 0 & 0 & 0 & 0 \\
\hline Tabebuia impetiginosa & Tahuari & 0.28 & 0 & 0 & 0 & 0 & 0 & 0 \\
\hline Tabebuia serratifolia & Tahuari & 0 & 0 & 0.62 & 0 & 0 & 0 & 0 \\
\hline Tabebuia sp. & Tahuari & 0 & 0.35 & 0.42 & 0.87 & 0.41 & 0.22 & 0 \\
\hline Tachigalia sp. & Tangarana & 0 & 0 & 0 & 0 & 0.58 & 0 & 0 \\
\hline Trattinickia glaziovii & Isigo & 0 & 0 & 0 & 0.60 & 0.13 & 0 & 0 \\
\hline Virola sebifera & Cumala & 0 & 0.28 & 0 & 0 & 0.09 & 0 & 0 \\
\hline Virola sp. & Cumala & 0 & 0 & 0.21 & 0.38 & 0 & 0 & 0 \\
\hline Vochysia sp. & Catuaba & 0 & 0 & 0 & 0.46 & 0.61 & 0.73 & 0 \\
\hline
\end{tabular}


Apéndice 6. Volúmenes promedio de madera extraídos por hectárea por año reportados oficialmente en las concesiones madereras de Tahuamanu

\begin{tabular}{|c|c|c|c|c|c|c|c|c|}
\hline Nombre científico & Nombre común & 2004 & 2005 & 2006 & 2007 & 2008 & 2009 & 2010 \\
\hline Acacia sp. & Vilco & 0 & 0 & 0.25 & 0 & 0 & 0 & 0 \\
\hline Amburana cearensis & Ishpingo & 0.14 & 0.24 & 0.07 & 0.24 & 0.51 & 0.16 & 0.13 \\
\hline Aniba sp. & Moena & 0 & 0.14 & 0.10 & 0.25 & 0.27 & 0 & 0 \\
\hline Apuleia leiocarpa & Ana caspi & 0 & 0 & 0 & 0.04 & 0.07 & 0.09 & 0.14 \\
\hline Apuleia mollaris & Ana caspi & 0 & 0 & 0 & 0 & 0 & 0 & 0 \\
\hline Aspidosperma macrocarpon & Pumaquiro & 0.01 & 0.24 & 0.27 & 0.15 & 0.22 & 0.01 & 0 \\
\hline Aspidosperma parvifolium & Quillobordon & 0 & 0 & 0 & 0 & 0.03 & 0 & 0 \\
\hline Aspidosperma subincanum & Quillobordon & 0 & 0 & 0 & 0.01 & 0 & 0.01 & 0.01 \\
\hline Aspidosperma vargasii & Quillobordon & 0 & 0 & 0.22 & 0.16 & 0 & 0 & 0 \\
\hline Astronium sp. & Palo baston & 0 & 0 & 0 & 0.02 & 0 & 0 & 0.01 \\
\hline Brosimum alicastrum / B. uleanum & Manchinga & 0 & 0 & 0 & 0 & 0 & 0 & 0.19 \\
\hline Brosimum lactescens & Manchinga & 0 & 0.02 & 0 & 0 & 0.04 & 0 & 0 \\
\hline Calophyllum brasiliense & Lagarto caspi & 0 & 0 & 0 & 0 & 0.02 & 0 & 0 \\
\hline Calycophyllum spruceanum & Capirona & 0 & 0 & 0 & 0 & 0.10 & 0.07 & 0.17 \\
\hline Cariniana domesticata & Cachimbo & 0 & 0 & 0 & 0 & 0 & 0 & 0.10 \\
\hline Cariniana sp. & Misa & 0 & 0 & 0 & 0 & 0.04 & 0 & 0 \\
\hline Cedrela odorata & Cedro & 0.03 & 0.35 & 0.19 & 0.22 & 0.26 & 0.04 & 0 \\
\hline Cedrelinga catenaeformis & Tornillo & 0 & 0.69 & 0.64 & 0.92 & 0.52 & 0.08 & 0 \\
\hline Ceiba pentandra & Huimba & 0 & 0.11 & 0.15 & 0 & 0 & 0 & 0 \\
\hline Chorisia integrifolia & Lupuna & 0 & 0 & 0.08 & 1.11 & 0.39 & 0.07 & 0.41 \\
\hline Copaifera paupera & Copaiba & 0 & 0 & 0 & 0.06 & 0 & 0 & 0 \\
\hline Copaifera reticulata & Copaiba & 0.11 & 0.43 & 0.05 & 0.18 & 0.15 & 0.18 & 0.21 \\
\hline Couratari guianensis & Misa & 0 & 0 & 0 & 0.54 & 0.08 & 0 & 0 \\
\hline Couratari macrosperma & Cachimbo & 0.18 & 0 & 0 & 0 & 0 & 0 & 0 \\
\hline Crepidospermun goudotianum & Palo baston & 0 & 0 & 0 & 0 & 0.01 & 0.02 & 0.01 \\
\hline Dipteryx alata & Shihuahuaco & 1.45 & 4.14 & 1.03 & 0.78 & 0 & 0 & 0 \\
\hline Dipteryx sp. & Shihuahuaco & 0 & 0 & 0.20 & 1.63 & 3.00 & 0.55 & 1.90 \\
\hline Dipteryx odorata & Charapilla & 0 & 0.82 & 2.08 & 1.09 & 3.93 & 1.45 & 0.01 \\
\hline Dipteryx micrantha & Shihuahuaco & 0 & 0 & 1.78 & 1.34 & 0 & 0.02 & 0 \\
\hline Erythroxylum catuaba & Catuaba & 0 & 0 & 0.05 & 0 & 0 & 0 & 0.04 \\
\hline Eschweilera coriácea & Misa & 0 & 0.02 & 0 & 0 & 0 & 0 & 0 \\
\hline Hura crepitans & Catahua & 0 & 0 & 0 & 0.03 & 0 & 0 & 0 \\
\hline Hymenaea courbaril & Azucar huayo & 0 & 0 & 0.04 & 0.09 & 0 & 0.01 & 0 \\
\hline Hymenaea oblongifolia & Yutubanco & 0 & 5.01 & 0.10 & 0.08 & 0 & 0 & 0 \\
\hline Hymenaea palustris & Azucar huayo & 0 & 0.04 & 0 & 0 & 0 & 0 & 0 \\
\hline Hymenaea sp. & Azucar huayo & 0.05 & 0.15 & 0.05 & 0.18 & 0.53 & 0.20 & 0.31 \\
\hline Jacaranda copaia & Achihua & 0 & 0 & 0 & 0.03 & 0 & 0 & 0 \\
\hline Manilkara bidentata & Quinilla & 0.13 & 0.89 & 0.12 & 0.17 & 0.04 & 0.07 & 0.06 \\
\hline Mezilaurus itauba & Itahuba & 0 & 0 & 0 & 0.01 & 0 & 0 & 0.05 \\
\hline Myroxylon balsamun & Estoraque & 0.20 & 0.48 & 0.17 & 0.78 & 0.47 & 0.08 & 0.09 \\
\hline Ocotea sp. & Moena & 0 & 0 & 0 & 0 & 0.01 & 0 & 0 \\
\hline Pseudobombax septenatum & Lupuna & 0 & 0 & 0 & 0 & 1.13 & 0 & 0 \\
\hline Qualea sp. & Catuaba & 0 & 0 & 0 & 0 & 0.25 & 0 & 0 \\
\hline Schizolobium sp. & Pashaco & 0 & 0.01 & 0.11 & 0.68 & 0.60 & 0 & 0.02 \\
\hline Swietenia macrophylla & Caoba & 0.36 & 0.25 & 0.13 & 0.34 & 0.16 & 0.15 & 0 \\
\hline Tabebuia rosea & Tahuari & 0.01 & 0 & 0 & 0 & 0 & 0 & 0 \\
\hline Tabebuia serratifolia & Tahuari & 0 & 0 & 0 & 0.02 & 0.11 & 0.01 & 0 \\
\hline Tabebuia sp. & Tahuari & 0 & 0.40 & 0.02 & 0.02 & 0.24 & 0.03 & 0.08 \\
\hline Terminalia oblonga & Yacuchapana & 0 & 0 & 0 & 0 & 0 & 0 & 0.07 \\
\hline Virola sp. & Cumala & 0 & 0 & 0 & 0.11 & 0 & 0 & 0 \\
\hline
\end{tabular}




\section{Apéndice 7. Volúmenes promedio de madera extraídos por hectárea por año reportados oficialmente en las} concesiones castañeras de Tambopata-Manu

\begin{tabular}{|c|c|c|c|c|c|c|c|c|}
\hline Nombre científicow & Nombre común & 2004 & 2005 & 2006 & 2007 & 2008 & 2009 & 2010 \\
\hline Acacia sp. & Vilco & 0 & 0 & 0 & 0 & 0 & 0 & 0 \\
\hline Amburana cearensis & Ishpingo & 0.16 & 0.13 & 0.24 & 0.29 & 0.23 & 0 & 0 \\
\hline Aniba gigantifolia & Moena amarilla & 0 & 0 & 0 & 0.69 & 0 & 0 & 0 \\
\hline Aniba panurensis & Moena alcanfor & 0.10 & 0 & 0 & 0 & 0 & 0 & 0 \\
\hline Aniba perutilis & Moena negra & 0 & 0 & 0 & 0.20 & 0 & 0 & 0 \\
\hline Aniba roseadora & Moena rosada & 0 & 0.03 & 0.00 & 0 & 0 & 0 & 0 \\
\hline Aniba sp. & Moena & 0.16 & 0.27 & 0.32 & 0.32 & 0.12 & 0.04 & 0 \\
\hline Apuleia leiocarpa & Ana caspi & 0.11 & 0.06 & 0.01 & 0.01 & 0 & 0 & 0 \\
\hline Apuleia mollaris & Ana caspi & 0.09 & 0 & 0 & 0.01 & 0 & 0 & 0 \\
\hline Aspidosperma macrocarpon & Pumaquiro & 0.35 & 0.26 & 0.23 & 0.38 & 0.09 & 0.03 & 0 \\
\hline Aspidosperma parvifolium & Quillobordon & 0 & 0 & 0 & 0 & 0 & 0 & 0 \\
\hline Aspidosperma subincanum & Quillobordon & 0 & 0 & 0.03 & 0.04 & 0.13 & 0 & 0 \\
\hline Aspidosperma vargasii & Quillobordon & 0.03 & 0 & 0 & 0 & 0 & 0 & 0 \\
\hline Astronium sp. & Palo baston & 0 & 0.13 & 0 & 0 & 0 & 0 & 0 \\
\hline Brosimum alicastrum / B. uleanum & Manchinga & 0 & 0.17 & 0.03 & 0.08 & 0.15 & 0 & 0 \\
\hline Brosimum lactescens & Manchinga & 0 & 0 & 0 & 0 & 0 & 0 & 0 \\
\hline Bursera graveolens & Palo santo & 0 & 0 & 0.01 & 0.24 & 0 & 0 & 0 \\
\hline Calophyllum brasiliense & Lagarto caspi & 0.13 & 0.11 & 0.22 & 0.19 & 0.16 & 0 & 0 \\
\hline Calycophyllum spruceanum & Capirona & 0.00 & 0.00 & 0.00 & 0 & 0 & 0 & 0 \\
\hline Cariniana domesticata & Cachimbo & 0 & 0 & 0 & 0 & 0 & 0 & 0 \\
\hline Cariniana sp. & Misa & 0 & 0 & 0 & 0 & 0 & 0 & 0 \\
\hline Castilla ulei & Goma & 0 & 0 & 0.05 & 0.17 & 0 & 0 & 0 \\
\hline Cedrela dugesii & Nogalillo & 0.28 & 0 & 0.10 & 0 & 0.10 & 0 & 0 \\
\hline Cedrela odorata & Cedro & 0.44 & 0.28 & 0.48 & 0.22 & 0.11 & 0.04 & 0 \\
\hline Cedrelinga catenaeformis & Tornillo & 3.11 & 2.07 & 2.45 & 1.91 & 2.29 & 0.39 & 0 \\
\hline Ceiba pentandra & Huimba & 0 & 0.36 & 0.24 & 0 & 0.06 & 0 & 0 \\
\hline Chimarrhis sp. & Papelillo & 0 & 0 & 0.02 & 0 & 0 & 0 & 0 \\
\hline Chorisia integrifolia & Lupuna & 0.53 & 0.24 & 0.69 & 1.11 & 0.52 & 0.25 & 0 \\
\hline Chorisia sp. & Lupuna & 0 & 0 & 0 & 0 & 0 & 0.04 & 0 \\
\hline Cinnamomun camphora & Alcanfor & 0.06 & 0.02 & 0.01 & 0 & 0.06 & 0 & 0 \\
\hline Clarisia racemosa & Mashonaste & 0.12 & 0.04 & 0.04 & 0.13 & 0.07 & 0 & 0 \\
\hline Copaifera officinalis & Copaiba & 0.21 & 0 & 0 & 0 & 0 & 0 & 0 \\
\hline Copaifera paupera & Copaiba & 0.00 & 0 & 0 & 0 & 0 & 0 & 0 \\
\hline Copaifera reticulata & Copaiba & 0.32 & 0.22 & 0.29 & 0.21 & 0.32 & 0.03 & 0 \\
\hline Copaifera sp. & Copaiba & 0.00 & 0.32 & 0 & 0 & 0 & 0 & 0 \\
\hline Cordia alliodora & Laurel & 0.04 & 0 & 0 & 0 & 0 & 0 & 0 \\
\hline Couratari guianensis & Misa & 0.36 & 1.57 & 1.01 & 0.52 & 0.89 & 0 & 0 \\
\hline Couratari macrosperma & Cachimbo & 0 & 0 & 0 & 0 & 0 & 0 & 0 \\
\hline Couratari sp. & Misa & 0 & 0 & 0.57 & 1.43 & 0.79 & 0.18 & 0 \\
\hline Couratarisp. & Tauari & 2.59 & 0 & 1.49 & 3.19 & 0 & 0 & 0 \\
\hline Crepidospermun goudotianum & Palo baston & 0 & 0 & 0 & 0 & 0 & 0 & 0 \\
\hline Dialium guianense & Palisangre & 0 & 0 & 0.03 & 0 & 0 & 0 & 0 \\
\hline Dipteryx alata & Shihuahuaco & 0 & 0.43 & 0.32 & 0 & 0 & 0 & 0 \\
\hline Dipteryx sp. & Shihuahuaco & 0 & 0 & 0 & 0 & 0 & 0 & 0 \\
\hline Dipteryx odorata & Charapilla & 0.32 & 0.53 & 0.53 & 0.30 & 0.61 & 0 & 0 \\
\hline Dipteryx micrantha & Shihuahuaco & 0.34 & 0.20 & 0.13 & 0 & 0 & 0 & 0 \\
\hline Erythroxylum catuaba & Catuaba & 0 & 0 & 0 & 0.22 & 0.13 & 0.05 & 0 \\
\hline Eschweilera coriacea & Misa & 0 & 0 & 0 & 0 & 0 & 0 & 0 \\
\hline Ficus guianensis & Renaco & 0.10 & 0 & 0.03 & 0.10 & 0.00 & 0.10 & 0 \\
\hline Ficus insipida & Oje & 0 & 0 & 0.09 & 0 & 0.07 & 0 & 0 \\
\hline
\end{tabular}




\begin{tabular}{|c|c|c|c|c|c|c|c|c|}
\hline Nombre científicow & Nombre común & 2004 & 2005 & 2006 & 2007 & 2008 & 2009 & 2010 \\
\hline Ficus killipii & Matapalo & 0 & 0 & 0.22 & 0.20 & 0 & 0 & 0 \\
\hline Ficus sp. & Oje & 0 & 0 & 0 & 0.20 & 0 & 0 & 0 \\
\hline Guarea guidonia & Requia & 0 & 0 & 0.01 & 0 & 0 & 0 & 0 \\
\hline Guarea trichiloides & Requia & 0 & 0 & 0.15 & 0.08 & 0.07 & 0 & 0 \\
\hline Guatteria elata & Carahuasca & 0 & 0 & 0 & 0 & 0.22 & 0 & 0 \\
\hline Hevea brasiliensis & Shiringa, jebe & 0.24 & 0 & 0 & 0 & 0 & 0 & 0 \\
\hline Huberodendron swietenoides & Achihua & 0.35 & 0.52 & 0.10 & 0.44 & 0.33 & 0.11 & 0 \\
\hline Hura crepitans & Catahua & 0.27 & 0.14 & 0.09 & 0.56 & 0.08 & 0.06 & 0 \\
\hline Hymenaea courbaril & Azucar huayo & 0.08 & 0 & 0 & 0.19 & 0 & 0 & 0 \\
\hline Hymenaea oblongifolia & Yutubanco & 0 & 0 & 0 & 0 & 0 & 0 & 0 \\
\hline Hymenaea palustris & Azucar huayo & 0 & 0 & 0 & 0 & 0 & 0 & 0 \\
\hline Hymenaea sp. & Azucar huayo & 0.37 & 0.14 & 0.12 & 0.18 & 0.07 & 0 & 0 \\
\hline Inga marginata & Pacae blanco & 0 & 0 & 0.01 & 0 & 0 & 0 & 0 \\
\hline Inga sp. & Shimbillo & 0.14 & 0.05 & 0.01 & 0.38 & 0 & 0 & 0 \\
\hline Jacaranda copaia & Achihua & 0.29 & 0.12 & 0.13 & 0.35 & 0 & 0 & 0 \\
\hline Juglans sp. & Nogal & 0.02 & 0 & 0 & 0 & 0 & 0 & 0 \\
\hline Manilkara bidentata & Quinilla & 0.14 & 0.04 & 0.10 & 0.02 & 0 & 0 & 0 \\
\hline Matisia cordata / Capparis angulata & Sapote & 0 & 0 & 0 & 0 & 0.05 & 0 & 0 \\
\hline Matisia sp. & Sapote & 0 & 0.24 & 0.13 & 0.33 & 0 & 0 & 0 \\
\hline Mezilaurus itauba & Itahuba & 0.01 & 0.05 & 0.24 & 0 & 0 & 0 & 0 \\
\hline Mezilaurus sp. & Itahuba & 0.15 & 0 & 0 & 0 & 0 & 0 & 0 \\
\hline Minquartia guianensis & Huacapu & 0.24 & 0 & 0 & 0 & 0 & 0 & 0 \\
\hline Myroxylon balsamun & Estoraque & 0.15 & 0.30 & 0.32 & 0.17 & 0.07 & 0 & 0 \\
\hline Myroxylon sp. & Palo peruano & 0 & 0 & 0.05 & 0.02 & 0 & 0 & 0 \\
\hline Nectandra rediculata & Laurel & 0 & 0.01 & 0 & 0 & 0 & 0 & 0 \\
\hline Nectandra sp. & Moena & 0.23 & 0 & 0 & 0 & 0 & 0 & 0 \\
\hline Ocotea jelskii & Ishpinguillo & 0 & 0.12 & 0.12 & 0.31 & 0.27 & 0 & 0 \\
\hline Ocotea marmellensis & Moena negra & 0.12 & 0 & 0 & 0 & 0 & 0 & 0 \\
\hline Ocotea sp. & Moena & 0 & 0 & 0.03 & 0.22 & 0 & 0 & 0 \\
\hline Ocotea undulata & Isma moena & 0 & 0 & 0 & 0.19 & 0 & 0 & 0 \\
\hline Ormosia sunkei & Huayruro & 0.89 & 0 & 0 & 0 & 0.00 & 0 & 0 \\
\hline Pithecellobium sp. & Pashaco colorado & 0 & 0 & 0.12 & 0.08 & 0 & 0 & 0 \\
\hline Podocarpus sp. & Romerillo & 0 & 0 & 0.02 & 0 & 0 & 0 & 0 \\
\hline "Por identificar" & Sacsa Cuti & 0 & 0 & 0.03 & 0.14 & 0 & 0 & 0 \\
\hline "Por identificar 22" & café con leche & 0.06 & 0 & 0 & 0 & 0 & 0 & 0 \\
\hline "Por identificar 7" & Aleton & 0.06 & 0.68 & 0.12 & 0.99 & 0.45 & 0.03 & 0 \\
\hline Pourouma cecropiaefolia & Uvilla & 0 & 0 & 0.01 & 0.03 & 0 & 0 & 0 \\
\hline Pouteria neglecta & Caimito & 0.08 & 0 & 0.05 & 0.75 & 0 & 0 & 0 \\
\hline Protium aracouchini & Isica & 0.12 & 0 & 0 & 0 & 0 & 0 & 0 \\
\hline Protium sp. & Copal, incienzo & 0.40 & 0.10 & 0.15 & 0.18 & 0.23 & 0 & 0 \\
\hline Pseudobombax septenatum & Lupuna & 0 & 0 & 0 & 0 & 0 & 0 & 0 \\
\hline Pseudolmedia laevis & Chimicua colorada & 0 & 0 & 0 & 0 & 0.05 & 0 & 0 \\
\hline Qualea sp. & Catuaba & 0 & 0 & 0 & 0 & 0 & 0 & 0 \\
\hline Quararibea cordata & Sapote & 0.08 & 0 & 0 & 0 & 0 & 0 & 0 \\
\hline Schizolobium amazonicum & Pino chuncho & 0 & 0 & 0.26 & 0.53 & 0.54 & 0 & 0 \\
\hline Schizolobium sp. & Pashaco & 0.41 & 0.77 & 0.62 & 0.72 & 0.30 & 0.15 & 0 \\
\hline Spondias mombin & Ubos & 0 & 0 & 0.01 & 0 & 0.02 & 0 & 0 \\
\hline Swietenia macrophylla & Caoba & 0.30 & 0.22 & 0.15 & 0.17 & 0.04 & 0 & 0 \\
\hline Tabebuia impetiginosa & Tahuari & 0.11 & 0 & 0 & 0 & 0 & 0 & 0 \\
\hline Tabebuia rosea & Tahuari & 0 & 0 & 0 & 0 & 0 & 0 & 0 \\
\hline Tabebuia serratifolia & Tahuari & 0 & 0 & 0 & 0 & 0 & 0 & 0 \\
\hline
\end{tabular}




\begin{tabular}{lllllllll}
\hline Nombre científicow & Nombre común & 2004 & 2005 & 2006 & 2007 & 2008 & 2009 & 2010 \\
Tabebuia sp. & Tahuari & 0.27 & 0.14 & 0.35 & 0.35 & 0.34 & 0 & 0 \\
Terminalia oblonga & Yacuchapana & 0 & 0 & 0 & 0 & 0 & 0 & 0 \\
Unonopsis matewsii & Maranon del monte & 0.24 & 0.06 & 0.24 & 0.64 & 0.05 & 0.00 & 0 \\
Virola sebifera & Cumala & 0.13 & 0.10 & 0.54 & 0.18 & 0.34 & 0.03 & 0 \\
Virola sp. & Cumala & 0.58 & 0.07 & 0.51 & 0.18 & 0.22 & 0 & 0 \\
Vismia sp. & Inca pacae & 0.06 & 0.08 & 0.06 & 0.08 & 0.18 & 0 & 0 \\
Vochysia sp. & Alkocaspi & 0 & 0 & 0.07 & 0 & 0 & 0 & 0 \\
\hline
\end{tabular}


Apéndice 8. Expertos consultados

\begin{tabular}{ll}
\hline Persona entrevistada & Cargo e institución que representa \\
\hline Ing. Gastón Chucos & Dirección General Forestal y de Fauna Silvestre \\
\hline Ph.D. Elsa Arias & Consultora Forestal \\
\hline Ing. Gilber Martínez & Coordinador de Campo de proyectos con castañeros, ACCA \\
\hline Ing. Junior Orrego & $\begin{array}{l}\text { Encargado del Área de Procesos Administrativos, Sancionador de la Administración } \\
\text { Técnica Tambopata-Manu }\end{array}$ \\
\hline Ing. Luis Bocanegra & Consejero Regional, Gobierno Regional de Madre de Dios \\
\hline Biol. Luz Marina Velarde & Asesora Técnica CAMDE-PERU \\
\hline M.Sc. Ronald Corvera & Investigador PROBOSQUES, IIAP \\
\hline
\end{tabular}




El objetivo de este documento es evaluar la situación normativa del aprovechamiento de madera en las concesiones castañeras de Madre de Dios desde el año 2004, cuando se publicó la norma con carácter de complementariedad que permitió esta actividad y hasta la zafra concluída para el año 2010. Para este fin se analizaron las cifras oficiales de volúmenes extraídos de madera tanto en concesiones castañeras y en concesiones madereras dentro de las Administraciones Técnicas de Tahuamanu y TambopataManu. Se sugiere que el carácter de complementariedad que actualmente permite extraer madera en concesiones castañeras en Madre de Dios se ha desvirtuado y en consecuencia, el objetivo inicial del establecimiento de estas concesiones. Se sugiere además que la aplicación de límites numéricos uniformes a las concesiones castañeras para la extracción de madera no es la mejor forma de guiar el manejo de ambos productos. Finalmente, se propone la necesidad de evaluar opciones para un manejo integrado de la madera y la castaña, enfocado más en buenas prácticas de aprovechamiento y menos en aspectos normativos poco flexibles. Todo esto unido a la implementación de procesos de diálogo entre los diferentes actores involucrados en el uso de los recursos forestales de Madre de Dios. hacia políticas y prácticas que afectan a los bosques de los países en vías de desarrollo. CIFOR es uno de 15 centros que forman el Grupo Consultivo sobre Investigación Agrícola Internacional (CGIAR por sus siglas en inglés). La sede principal de CIFOR se encuentra en Bogor, Indonesia. El centro también cuenta con oficinas en Asia, África y Sudamérica. 